\title{
NMDA Receptor-Mediated Control of Presynaptic Calcium and Neurotransmitter Release
}

\author{
Amanda J. Cochilla and Simon Alford \\ Department of Physiology and Northwestern University Institute for Neuroscience, Northwestern University Medical \\ School, Chicago, Illinois 60611
}

Before action potential-evoked $\mathrm{Ca}^{2+}$ transients, basal presynaptic $\mathrm{Ca}^{2+}$ concentration may profoundly affect the amplitude of subsequent neurotransmitter release. Reticulospinal axons of the lamprey spinal cord receive glutamatergic synaptic input. We have investigated the effect of this input on presynaptic $\mathrm{Ca}^{2+}$ concentrations and evoked release of neurotransmitter. Paired recordings were made between reticulospinal axons and the neurons that make axo-axonic synapses onto those axons. Both excitatory and inhibitory paired-cell responses were recorded in the axons. Excitatory synaptic inputs were blocked by the AMPA receptor antagonist 6-cyano-7-nitroquinoxaline2,3-dione (CNQX; $10 \mu \mathrm{M}$ ) and by the NMDA receptor antagonist 2-amino-5-phosphonopentanoate (AP-5; $50 \mu \mathrm{M}$ ). Application of NMDA evoked an increase in presynaptic $\mathrm{Ca}^{2+}$ in reticulospinal axons. Extracellular stimulation evoked $\mathrm{Ca}^{2+}$ transients in axons when applied either directly over the axon or lateral to the axons. Transients evoked by the two types of stimulation dif-

Presynaptic modulation is a widespread phenomenon in the CNS that occurs on many different time frames, from milliseconds (Swandulla et al., 1991; Smith et al., 1993; Tank et al., 1995) to days (Bliss and Lomo, 1973; Ekerot and Kano, 1985; Ito, 1989; Bliss and Collingridge, 1993). A leading model for presynaptic facilitation of neurotransmitter release is that elevated residual $\mathrm{Ca}^{2+}$ remains bound to release sites between action potentials (Katz and Miledi, 1968; Kamiya and Zucker, 1994; Bertram, 1997). Short-term enhancement of synaptic transmission involving sustained presynaptic $\mathrm{Ca}^{2+}$ concentrations may also be $\mathrm{Na}^{+}$ dependent (Mulkey and Zucker, 1992; Delaney and Tank, 1994). Alternatively, at many synapses, including the Xenopus neuromuscular junction (Fu and Huang, 1994) and synapses in the rat amygdala (Huang et al., 1996), cerebellum (Sabatini and Regehr, 1995), and hippocampus (Sabria et al., 1995), presynaptic enhancement of release is mediated by increased presynaptic $\mathrm{Ca}^{2+}$ conductance. Release of $\mathrm{Ca}^{2+}$ from intracellular stores has also been implicated in presynaptic facilitation in goldfish retina

Received July 30, 1998; revised Oct. 9, 1998; accepted Oct. 15, 1998.

This work was supported by National Institute of Neurological Disorders and Stroke Grants NS31713 and NS32114. We would like to thank Drs. N. T. Slater and N. E. Schwartz for help in this study and comments on this manuscript. We would also like to thank J. Hsu for his help in reconstructing confocal data sets.

Correspondence should be addressed to Dr. Simon Alford, Department of Physiology, Northwestern University Medical School, 303 East Chicago Avenue, Chicago, IL 60611.

Dr. Cochilla's present address: Department of Physiology and Biophysics, University of Colorado Medical School, 4200 East Ninth Avenue Box C240, Denver, CO 80262 .

Copyright (C) 1998 Society for Neuroscience $\quad 0270-6474 / 98 / 190193-13 \$ 05.00 / 0$ fered in magnitude and sensitivity to AP-5. Simultaneous microelectrode recordings from the axons during $\mathrm{Ca}^{2+}$ imaging revealed that stimulation of synaptic inputs directed to the axons evoked $\mathrm{Ca}^{2+}$ entry. By the use of paired-cell recordings between reticulospinal axons and their postsynaptic targets, NMDA receptor activation was shown to enhance evoked release of transmitter from the axons that received axoaxonic inputs. When the synaptic input to the axon was stimulated before eliciting an action potential in the axon, transmitter release from the axon was enhanced. We conclude that NMDA receptor-mediated input to reticulospinal axons increases basal $\mathrm{Ca}^{2+}$ within the axons and that this $\mathrm{Ca}^{2+}$ is sufficient to enhance release from the axons.

Key words: presynaptic calcium; glutamate receptor; NMDA receptor; non-NMDA receptor; transmitter release; presynaptic modulation

(Kobayashi et al., 1995) and lamprey spinal cord (Cochilla and Alford, 1998).

In the lamprey, reticulospinal axons make glutamatergic synapses with spinal neurons. These synapses comprise mixed electrical and chemical contacts with dendrites throughout the spinal cord (Rovainen, 1974; Brodin et al., 1988). Consequently, recording from these axons is electrotonically equivalent to recording within the terminal (Ringham, 1975). At the lamprey reticulospinal axon-motoneuron synapse, facilitation of release occurs when metabotropic glutamate receptors activate $\mathrm{Ca}^{2+}$-dependent $\mathrm{Ca}^{2+}$ release from internal stores (Cochilla and Alford, 1998). These reticulospinal axons also receive excitatory synaptic input (Cochilla and Alford, 1997) mediated by glutamate acting at AMPA and NMDA receptors.

Ionotropic receptors located at the presynaptic terminal may alter transmission from the terminal by altering the $\mathrm{Ca}^{2+}$ concentration before action potential invasion. This mechanism of enhancement of neurotransmitter release has been proposed for nicotinic receptors in mossy fiber terminals of the hippocampus (Gray et al., 1996). Ionotropic glutamate receptors, including kainate receptors (Agrawal and Evans, 1986; Dev et al., 1996; Clarke et al., 1997; Kamiya and Ozua, 1998), NMDA receptors (Berretta and Jones, 1996; Aoki et al., 1997; Conti et al., 1997; Liu et al., 1997; Carlton et al., 1998; Chen et al., 1998; Robert et al., 1998), NMDA-like receptors (Smirnova et al., 1993), and AMPA receptors (Barnes et al., 1994; Farb et al., 1995; Bureau and Mulle, 1998) have now been identified at presynaptic terminals throughout the vertebrate neuroaxis. Their actions in locations as diverse as the entorhinal cortex and the spinal dorsal horn may be 
critical in damping neuronal excitability involved in epilepsy and the regulation of pain pathways. These receptors might also modulate release by altering presynaptic $\mathrm{Ca}^{2+}$ concentrations. This alteration could be either direct, by activating NMDA receptors or $\mathrm{Ca}^{2+}$-permeable AMPA or KA receptors, or indirect, by depolarizing the terminal to activate presynaptic voltageoperated $\mathrm{Ca}^{2+}$ channels (VOCCs).

We have investigated the role of presynaptic glutamate receptors in modulating transmitter release from lamprey reticulospinal axons. We conclude that axo-axonic activation of presynaptic NMDA receptors enhances release from these axons by a $\mathrm{Ca}^{2+}$ dependent mechanism.

Parts of this paper have been published previously (Holt et al., 1996).

\section{MATERIALS AND METHODS}

The preparation. Lamprey ammoceotes (Petromyzon marinus) were anesthetized with tricaine methyl sulfonic acid (MS222; $100 \mathrm{mg} / \mathrm{l}$ ), and sections of the spinal cord were removed in accordance with institutional guidelines. After removal, the tissue was maintained at $10^{\circ} \mathrm{C}$ in Ringer's solution containing (concentration in $\mathrm{mM}$ ): $\mathrm{NaCl}, 100 ; \mathrm{KCl}, 2.1 ; \mathrm{CaCl}_{2}$, 2.6; $\mathrm{MgCl}_{2}, 1.8$; glucose, 4 ; and $\mathrm{NaHCO}_{3}, 26$ (adapted from Wickelgren, 1977). The Ringer's solution was bubbled with $95 \% \mathrm{O}_{2} / 5 \% \mathrm{CO}_{2}$ to a $\mathrm{pH}$ of 7.4. Whole-cell patch-clamp recordings were achieved using the blind technique (Blanton et al., 1989; Alford and Dubuc, 1993) with pipettes pulled to a DC tip resistance of 5-10 M $\Omega$ and filled with patch solution containing (concentration in $\mathrm{mM}$ ): cesium methane sulfonate, 102.5; $\mathrm{NaCl}, 1 ; \mathrm{MgCl}_{2}, 1$; EGTA, 5; and HEPES, 5. For sharp microelectrode intracellular recordings, electrodes were pulled to a DC tip resistance of 20-30 M $\Omega$ when filled with $3 \mathrm{~m}$ potassium methylsulfate. Drugs were administered by bath application. For experiments in which only electrophysiological measurements were made, the tissue was pinned ventral side up in a cooled Sylgard-floored chamber to expose the ventromedial Reticulospinal axons for intracellular and patch recording. The flow rate in the bath was $\sim 1 \mu \mathrm{l} / \mathrm{min}$, and the total volume of the chamber and access tubing was $1.1 \mathrm{ml}$.

Imaging experiments. The dextran amine-conjugated form of the $\mathrm{Ca}^{2+}$ indicator dye Oregon green 488 BAPTA-1 (OGB-1; Molecular Probes, Eugene, OR) was used to label the axons retrogradely. This labeling was accomplished by fitting a suction electrode filled with dye over a cut end of the spinal cord immediately after cutting the spinal cord. The tissue was then allowed to incubate overnight, during which time the dye was transported throughout the large reticulospinal axons in the spinal cord. Imaging experiments were performed with a confocal microscope (MRC600; Bio-Rad, Hercules, CA). Images were obtained using a 20×, 0.75 numerical aperture Fluor lens (Nikon). The $488 \mathrm{~nm}$ line of an argon ion laser was used as an excitor source through a neutral density filter. Imaging of evoked events was then performed by sampling twodimensional arrays of data $(192 \times 128$ pixels $)$ at $2 \mathrm{~Hz}$. Images for data from wash-in of agonist were sampled at $10 \mathrm{sec}$ intervals. Higher speed microfluometric recording was achieved by scanning repetitively the excitor laser over the same line location at $500 \mathrm{~Hz}$.

Analysis of the imaging data was performed on a Macintosh computer using NIH Image software. NIH Image was used to calculate the brightness value (range, $0-255$ per 8 bit) for each pixel in the field of view. For each individual axon of interest, the average brightness value within the axon was measured, and background brightness (mode of the entire field of view) was subtracted. The data were then normalized to the baseline fluorescence to give $\Delta F / F$ values, where 1 is the baseline value. Statistical analysis was performed using either Microsoft Excel or IgorPro (WaveMetrics).

\section{RESULTS}

\section{Reticulospinal axons have synaptic NMDA receptors}

Previously, we have demonstrated that lamprey reticulospinal axons receive glutamatergic synaptic input from other neurons in the spinal cord (Cochilla and Alford, 1997). This input is mediated by NMDA and AMPA receptors. Paired axonal recordings between reticulospinal axons and their presynaptic inputs were made to demonstrate the nature of the synaptic input directly
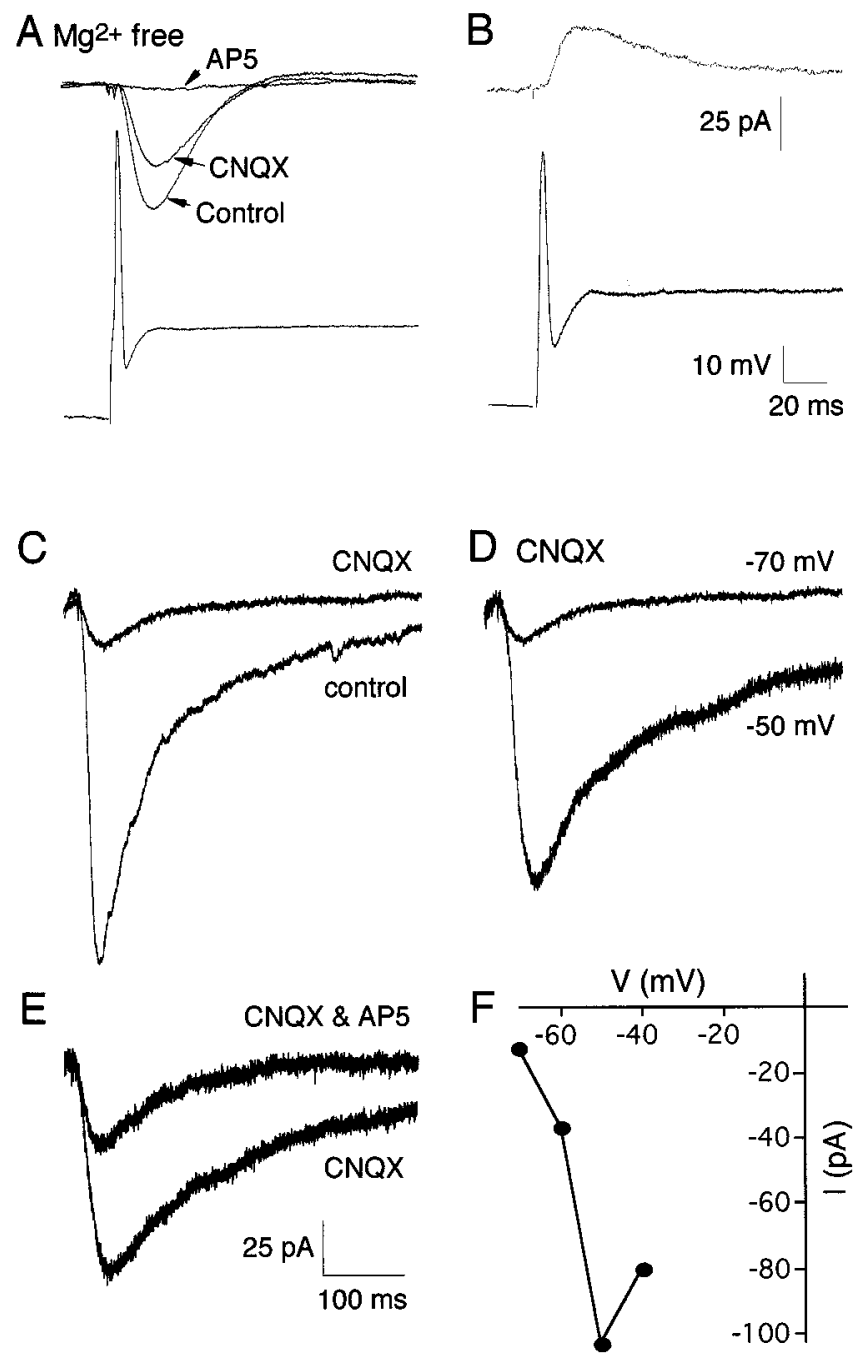

Figure 1. Reticulospinal axons receive glutamatergic synaptic inputs that act on AMPA and NMDA receptors. Paired recordings were made between presynaptic neurons and postsynaptic axons. Postsynaptic axons were held under voltage clamp with a patch electrode, and presynaptic neurons were held under current clamp with a microelectrode. $A$, A spike induced in a presynaptic neuron by depolarizing current injection (lower trace) evoked an EPSC in the postsynaptic axon (upper trace). Application of $C N Q X(10 \mu \mathrm{M})$ reduced the amplitude of the postsynaptic axonal EPSC. The remaining component of the EPSC was abolished by the addition of $A P-5$ (100 $\mu \mathrm{M}$; recording was in Ringer's solution with no added $\left.\mathrm{Mg}^{2+}\right) . B$, Recordings from the same postsynaptic axon as in $A$ and a different presynaptic neuron are shown. In this case, stimulation of the presynaptic neuron evoked an IPSC in the postsynaptic axon. $C$, In another postsynaptic axon, the spinal cord was stimulated to evoke a compound EPSC (the tissue was superfused with Ringer's solution containing $2.6 \mathrm{mM} \mathrm{MgCl}$ and $10 \mu \mathrm{M}$ bicuculline $)$. Addition of $C N Q X(10 \mu \mathrm{M})$ reduced the amplitude of the response. $D$, The $C N Q X$-insensitive component of the EPSC was larger when recorded at $-50 \mathrm{mV}$ than when recorded at $-70 \mathrm{mV}$. E, This component was reduced by the addition of $A P-5(50 \mu \mathrm{M})$ to the Ringer's solution (recorded at a holding potential of $-40 \mathrm{mV}) . F$, Voltage-current plot of the peak amplitude of the evoked EPSC between holding potentials of -40 and $-70 \mathrm{mV}$ in normal Ringer's solution is shown. Note that the amplitude of the synaptic response increases with decreasing holding potentials, indicating that $\mathrm{Mg}^{2+}$ block of the channel is being relieved at depolarized potentials.

(Fig. 1). An axon was held under voltage clamp with a patch electrode, and a presynaptic neuron was recorded under current clamp with a microelectrode. Both inward and outward synaptic currents were recorded at holding potentials of $-70 \mathrm{mV}$ in the 
voltage-clamped axons in response to stimulation of different presynaptic axons. Responses recorded in one axon in response to action potentials evoked in two different presynaptic axons are demonstrated (Fig. $1 A, B$ ). For the excitatory input, application of 6-cyano-7-nitroquinoxaline-2,3-dione (CNQX; $10 \mu \mathrm{M}$ ) significantly reduced the amplitude of the evoked paired EPSC (reduced to $58.6 \pm 6.7 \%$ of control; $p<0.001 ; n=7$ pairs; Fig. $1 A$ ). In two of the pairs in which CNQX was applied the NMDA receptor antagonist 2-amino-5-phosphonopentanoate (AP-5) was subsequently added to the superfusate. This further reduced the amplitude of the remaining response (reduced to $11 \%$ of control amplitude).

The AP-5-sensitive component of the EPSC that remains in CNQX was investigated using recordings from 17 reticulospinal axons. Recordings were made in the presence of bicuculline (10 $\mu \mathrm{M})$ to block GABAergic input to the axons. Stimulation of the spinal cord lateral to the axon tracts $(1 \mathrm{msec}$ stimuli at $<15 \mathrm{pA})$ evokes the excitatory synaptic input to the axon (Cochilla and Alford, 1997). This response is sensitive to CNQX (10 $\mu \mathrm{M} ; n=$ 17 out of 17 ; Fig. $1 C$ ). If the remaining component were NMDA receptor-mediated, then the current-voltage relationship in the presence of extracellular $\mathrm{Mg}^{2+}$ should have a negative slope at membrane potentials negative to $-40 \mathrm{mV}$, indicating that $\mathrm{Mg}^{2+}$ block of the NMDA channel is relieved as the membrane is depolarized. To test this hypothesis, we stepped the membrane potential of the axon in $10 \mathrm{mV}$ increments from -70 to $-40 \mathrm{mV}$, and an EPSC was evoked at each holding potential (Fig. 1D). The amplitude of the EPSC increased as the membrane potential was depolarized ( $n=6$ out of 11 ). This region of negative slope in the voltage-current relationship (Fig. $1 F$ ) indicates that the response is voltage dependent in a manner equated with NMDA receptormediated synaptic transmission in neuronal dendrites and somata. This voltage-dependent component of the response is reduced by the NMDA receptor antagonist AP-5 (50 $\mu \mathrm{M} ; n=4$ out of 4 ; reduced to $55.5 \pm 3.7 \%$ of control; Fig. $1 E$ ), and the response was invariably enhanced after the removal of $\mathrm{Mg}^{2+}$ from the superfusate ( $n=7$ out of 7 ) (see also Cochilla and Alford, 1997). At holding potentials more depolarized than -40 $\mathrm{mV}$, a steady-state voltage-activated outward current was recorded in the axons. This current was not blocked by intracellular $\mathrm{Cs}^{+}$, intracellular QX-314 (1 mM), or intracellular 4-AP (1 mM). This current impeded voltage clamp of the axons, obscured the synaptic response at depolarized potentials, and prevented the acquisition of a voltage-current relationship for the response at potentials more depolarized than $-40 \mathrm{mV}$. Nonetheless the sensitivity to AP-5 and the negative slope of the current-voltage relationship between -70 and $-40 \mathrm{mV}$ indicate that this component of the EPSC is mediated by glutamate acting at NMDA receptors on the reticulospinal axon.

\section{Presynaptic NMDA receptors cause presynaptic $\mathrm{Ca}^{2+}$ entry}

Because NMDA receptors are permeable to $\mathrm{Ca}^{2+}$ (MacDermott et al., 1986), activation of these receptors in axons has the potential to alter presynaptic $\mathrm{Ca}^{2+}$ levels within the axons. To test this hypothesis directly, we retrogradely labeled axons with the fluorescent $\mathrm{Ca}^{2+}$ indicator dye OGB-1, and fluorescence levels were monitored during NMDA wash-in and wash-out (Fig. 2). These experiments were performed in the presence of TTX $(1 \mu \mathrm{M})$ to block $\mathrm{Na}^{+}$action potentials. All of the axons in the field of view $(n=7$; Fig. $2 B)$ increased in brightness during NMDA wash-in (500 $\mu \mathrm{M}$; brightness increased by $30 \%$ ). Brightness levels de-
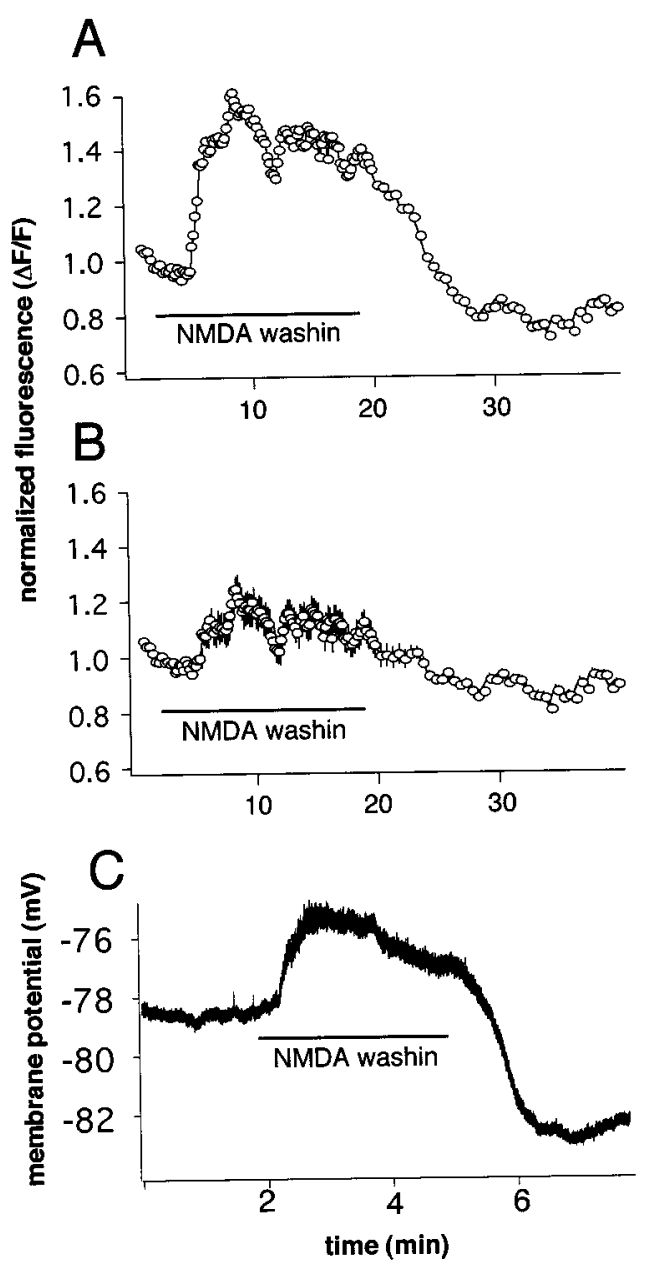

Figure 2. $N M D A$ evokes a $\mathrm{Ca}^{2+}$ transient. Axons were loaded with the $\mathrm{Ca}^{2+}$ indicator dye OGB-1. NMDA $(500 \mu \mathrm{M})$ was washed into the bath in the presence of TTX $(1 \mu \mathrm{M})$, causing an increase in fluorescence in the axons. $A$, Normalized fluorescence of one axon was recorded before, during, and after wash-in of $N M D A$. $B$, Normalized fluorescence of seven axons is shown before, during, and after $N M D A$ wash-in. $C, N M D A$ wash-in will depolarize the axons by $\sim 2-3 \mathrm{mV}$, which is not a substantial enough depolarization to allow $\mathrm{Ca}^{2+}$ entry through VOCCs. A representative axon recorded using a sharp microelectrode (recording made in $1 \mu \mathrm{M})$ TTX) is shown. Bath application of $N M D A$ led to a small depolarization $(3 \mathrm{mV})$ in this example, followed by an afterhyperpolarization.

creased to baseline after wash-out of NMDA. The effect of wash-in of NMDA was also tested for effect against depolarization of the axons. Axons were recorded in the presence of TTX (1 $\mu \mathrm{M})$ using sharp microelectrodes containing cesium methylsulfate (3 M). All of the axons demonstrated a depolarization on application of NMDA (500 $\mu \mathrm{M}$; largest depolarization, $9 \mathrm{mV}$; mean, $5.7 \pm 1.4 \mathrm{mV}$ from a mean resting membrane potential of $76.3 \pm$ $0.9 \mathrm{mV} ; n=4$; Fig. $2 C$ ). This depolarization is insufficient to activate VOCCs in these axons because the axons do not show any macroscopic $\mathrm{Ca}^{2+}$ channel activation at membrane potentials negative to $-40 \mathrm{mV}$ (Cochilla and Alford, 1998). We conclude that $\mathrm{Ca}^{2+}$ may enter presynaptic elements through NMDA receptor ion channels.

\section{Stimulus-evoked presynaptic $\mathrm{Ca}^{2+}$ transients have an} NMDA receptor-mediated component

Experiments were then performed to determine whether stimulus-induced $\mathrm{Ca}^{2+}$ transients in the axons were mediated 
A

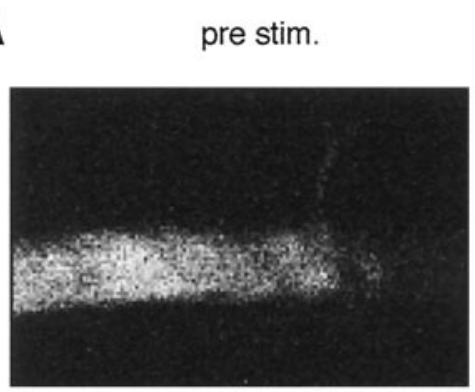

peak

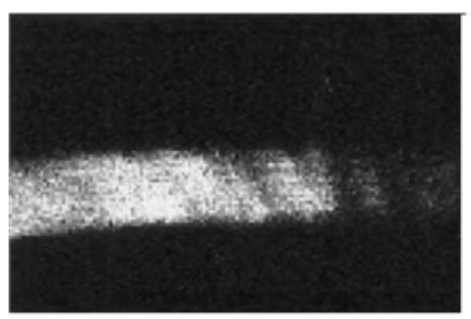

post stim.

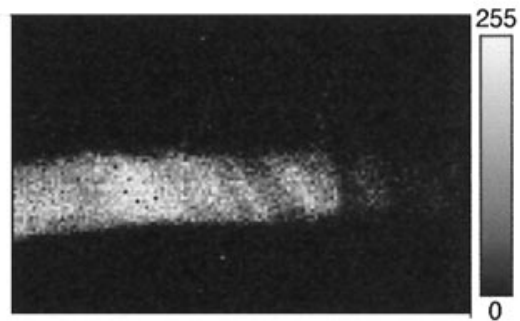

B

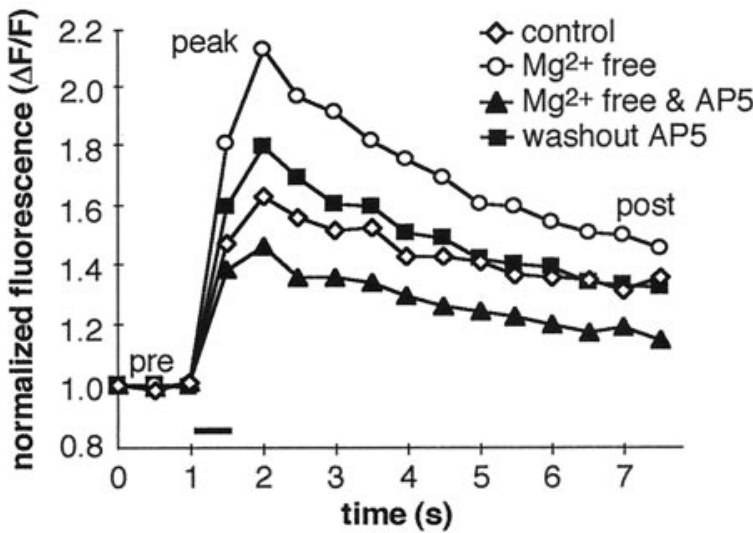

C

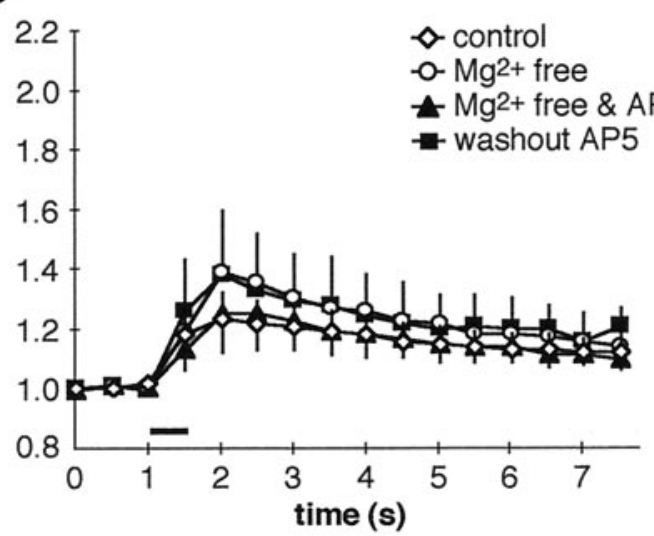

Figure 3. $\mathrm{Ca}^{2+}$ transients recorded in axons are sensitive to $\mathrm{Mg}^{2+}$ and $A P-5 . A$, An axon was filled with OGB-1 dye, and we recorded the response to a train of stimuli $(50 \mathrm{~Hz}$ stimulation for $0.5 \mathrm{sec})$ applied to the spinal cord. Left, The baseline fluorescence. Middle, The peak fluorescence. Right, The fluorescence $5 \mathrm{sec}$ after stimulation (stim.). The field is $53 \times 80 \mu \mathrm{m}$ in size. $B$, The normalized brightness within the axon is graphed at $0.5 \mathrm{sec}$ intervals. The stimulus was delivered at the time indicated by the horizontal bar. Responses in normal superfusate, in $\mathrm{Mg}^{2+}$-free superf usate, after addition of $A P-5$ $(50 \mu \mathrm{M})$ to the $\mathrm{Mg}^{2+}$-free superfusate, and after wash-out of $A P-5$ are shown. The images in $A$ were taken at the times indicated in the graph ( pre, peak, and post). $C$, The normalized brightness for a group of axons is shown. The stimulus was delivered at the time indicated by the horizontal bar. Responses in normal Ringer's solution $(n=12)$, in $\mathrm{Mg}^{2+}$-free Ringer's solution $(n=12)$, after addition of $A P-5(50 \mu \mathrm{M} ; n=6)$ to the $\mathrm{Mg}^{2+}$-free Ringer's solution, and after wash-out of $A P-5(n=3)$ are shown. Graph data are mean \pm SE. There is a significant difference in the peak brightness between responses measured in control versus $\mathrm{Mg}^{2+}$-free $(p<0.05)$ and in $\mathrm{Mg}^{2+}$-free versus $A P-5(p<0.02)$.

directly by $\mathrm{Ca}^{2+}$-permeable NMDA receptors. Axons were filled with OGB-1, and the spinal cord was stimulated lateral to the axon tracts ( $1 \mathrm{msec}$ stimuli at $50 \mathrm{~Hz}$ for $0.5 \mathrm{sec}$ ) to activate synaptic inputs to the axons. This stimulation elicits a $\mathrm{Ca}^{2+}$ transient in the axons that is sensitive to external $\mathrm{Mg}^{2+}$. In the axon shown (Fig. $3 A, B$ ) the amplitude of the $\mathrm{Ca}^{2+}$ transient in $\mathrm{Mg}^{2+}$-free Ringer's solution was $176.2 \%$ of control. The further addition of AP-5 $(50 \mu \mathrm{M})$ to the $\mathrm{Mg}^{2+}$-free superfusate decreased the response amplitude to $31.5 \%$ of the amplitude in $\mathrm{Mg}^{2+}$-free saline (Fig. $3 B$ ). For a group of axons, wash-out of $\mathrm{Mg}^{2+}$ from the control Ringer's solution increased the response to $166.4 \%$ of the amplitude in that control solution $(p<0.05 ; n=12$; Fig. $3 C)$. Addition of AP-5 $(50 \mu \mathrm{M})$ to the $\mathrm{Mg}^{2+}$-free Ringer's solution decreased the response to $60.3 \%$ of the amplitude recorded in $\mathrm{Mg}^{2+}$-free saline $(p<0.02 ; n=6)$. The reduction induced by AP-5 was reversible; wash-out of AP-5 into $\mathrm{Mg}^{2+}$-free Ringer's solution increased the response back to $152.4 \%$ of the control amplitude ( $n=3$; data not shown). The $\mathrm{Mg}^{2+}$ sensitivity of the response may be caused by $\mathrm{Mg}^{2+}$ acting at presynaptic voltageoperated channels or by $\mathrm{Mg}^{2+}$-dependent block of the NMDA receptor. However, the sensitivity of the response to the application of AP-5 clearly indicates that axonal NMDA receptors participate in the response of the axons to a train of stimuli applied to the spinal cord.

\section{Axons show both spike-induced $\mathrm{Ca}^{2+}$ entry and synaptically activated $\mathrm{Ca}^{2+}$ entry}

During experiments involving single-stimulus locations alone, it was not possible to determine whether extracellular stimulation lateral to the axons evoked action potentials in the reticulospinal axons. Consequently, stimulus-evoked $\mathrm{Ca}^{2+}$ entry into the axons may have resulted either from the activation of excitatory axoaxonic synapses (Cochilla and Alford, 1997) or from activation of VOCCs. Experiments were performed to determine whether the $\mathrm{Ca}^{2+}$ entry into the axon was caused by synaptic activation of NMDA receptors at axo-axonic synapses. If so, $\mathrm{Ca}^{2+}$ entry caused by a direct axonal stimulus should differ from $\mathrm{Ca}^{2+}$ entry caused by an indirect stimulus involving the activation of an axo-axonic synapse. Direct stimulation of the axons will evoke action potentials in the axons and cause $\mathrm{Ca}^{2+}$ entry through VOCCs, whereas indirect stimulation of the spinal cord lateral to the axons should activate neurons that synapse onto the axons and cause $\mathrm{Ca}^{2+}$ entry through synaptic receptors. To test this hypothesis, we used two electrodes to stimulate the tissue both directly over the axon tracts (direct stimulus) and lateral to the axon tracts (indirect stimulus; see Fig. $4 A$ for schematic of recording setup). Axons were retrogradely labeled with the $\mathrm{Ca}^{2+}$ indicator dye OGB-1, and the spinal cord was stimulated to elicit $\mathrm{Ca}^{2+}$ transients in the axons. These experiments were performed 

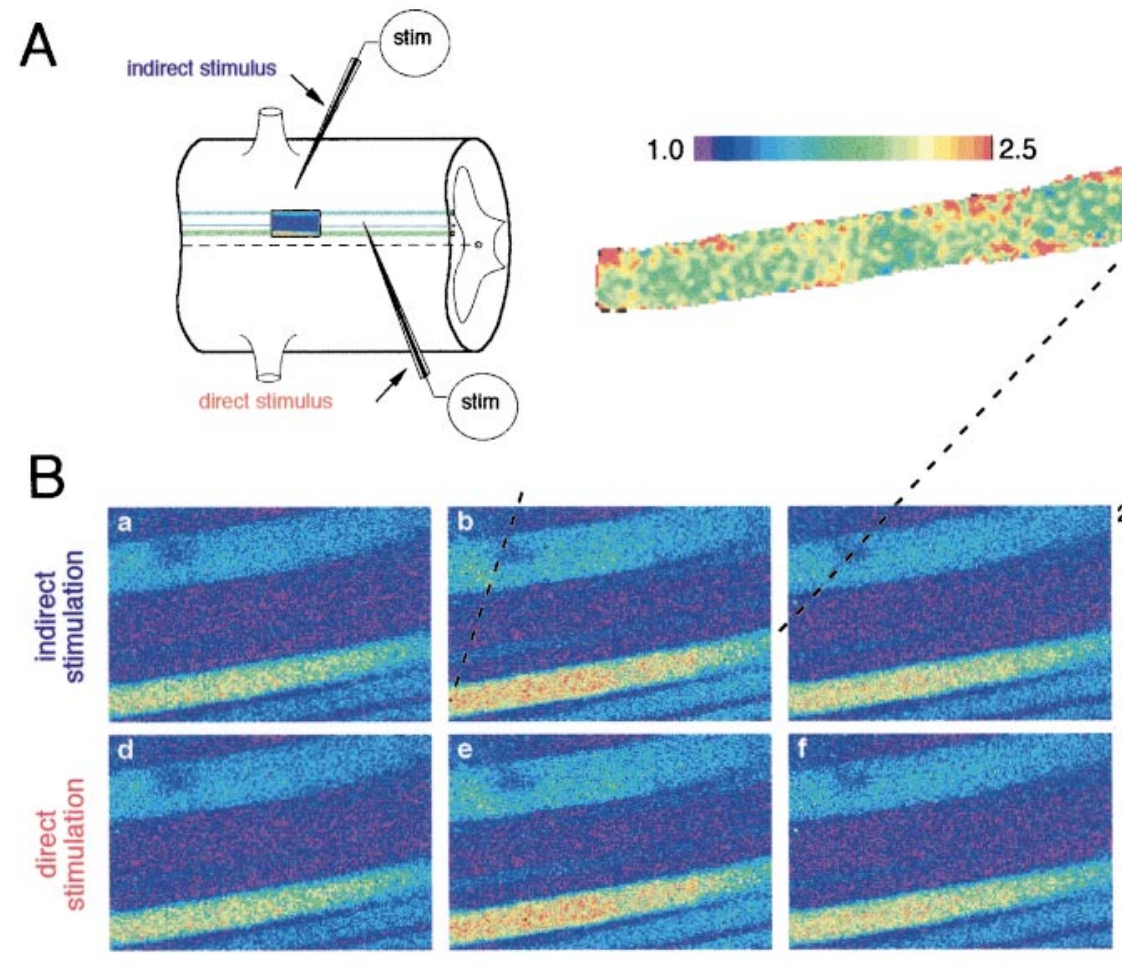

\section{Ci indirect stimulation}

\section{$\mathrm{C}_{\mathrm{ii}}$}

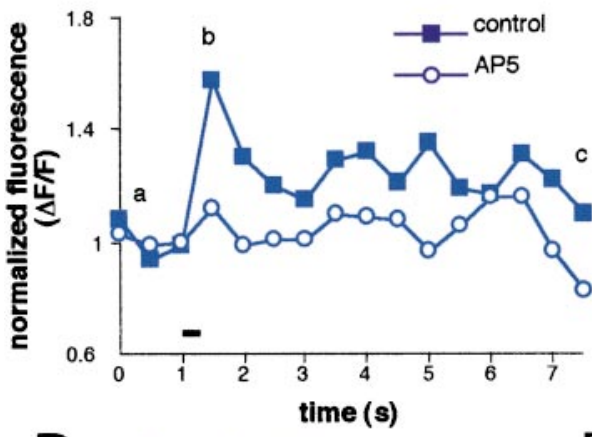

Di indirect stimulation

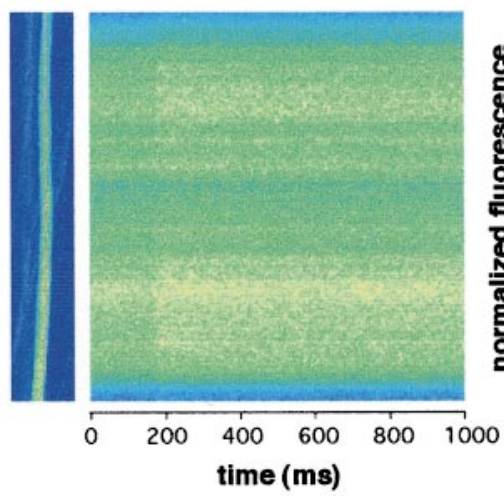

Dii
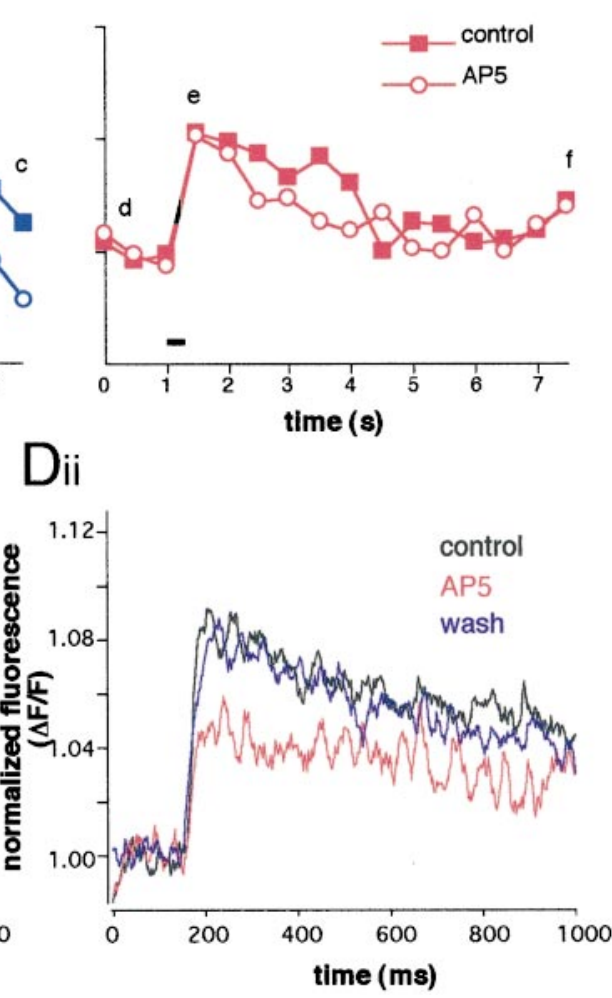

Figure 4. $\mathrm{Ca}^{2+}$ transients evoked by direct and indirect stimulation. $A$, Schematic of recording setup showing stimulating electrodes (stim) positioned to activate reticulospinal axons directly and indirectly. Imaging was performed from the region within the box. $B$, Images of axonal $\mathrm{Ca}^{2+}$ recorded before $(a, d)$, during $(b, e)$, and after $(c$, $f)$ stimulation of the spinal cord. $a-c$, The response to indirect stimulation. $d-f$, The response to direct stimulation. Each panel is $105 \times 70 \mu \mathrm{m}$ large. The inset shown above exploded from $b$ shows a pseudocolor representation of the normalized fluorescence change during the stimulus. This data compares $b$ with the prestimulus condition in $a \mathrm{Ci}$, Normalized fluorescence from the bottom-most axon shown in the field in $B$. The response of the axon to indirect stimulation is shown for images recorded in normal Ringer's solution and in the presence of $A P-5(50 \mu \mathrm{M})$. Cii, Normalized fluorescence from the same axon in response to direct stimulation. Fluorescence from images recorded in normal Ringer's solution and in the presence of $A P-5(50 \mu \mathrm{M})$ are shown. $D i$, In another preparation, an investigation of the response of a single axon to one indirect stimulus. A single line was repetitively scanned along a length of the axon at $500 \mathrm{~Hz}$. The spinal cord adjacent to the axon was stimulated to evoke a $\mathrm{Ca}^{2+}$ transient. Dii, The graphs were generated by measuring the fluorescence at each time point and normalizing this to the prestimulus level to show the rise in axonal $\mathrm{Ca}^{2+}$. The addition of $A P-5(50 \mu \mathrm{M})$ significantly reduced the amplitude of the evoked transient. The response recovered to control amplitude after washout of $A P-5$. in $\mathrm{Mg}^{2+}$-free Ringer's solution and in the presence of CNQX (10 $\mu \mathrm{M})$. Both direct and indirect stimulation elicited $\mathrm{Ca}^{2+}$ transients in the axon (Fig. $4 B, C$ ). In nine axons tested, the amplitude of $\mathrm{Ca}^{2+}$ transients elicited by indirect stimulation was $42.5 \pm 3.2 \%$ of those elicited by direct stimulation ( $p<0.002$; Figs. $4 C, 5 A)$. The indirectly activated $\mathrm{Ca}^{2+}$ transient was decreased to $45.9 \pm$
$3.8 \%$ of the control amplitude when AP-5 was added to the superfusate $(50 \mu \mathrm{M} ; p<0.05 ; n=4$; stimulus at $50 \mathrm{~Hz}, 0.2 \mathrm{sec}$; Figs. $4 C, 5 B)$. The amplitude reduction induced by AP-5 was reversible. On wash-out of AP-5, the amplitude of the $\mathrm{Ca}^{2+}$ transient increased to $95.3 \%$ of the amplitude recorded in control solution. In the same four axons, the directly activated $\mathrm{Ca}^{2+}$ 

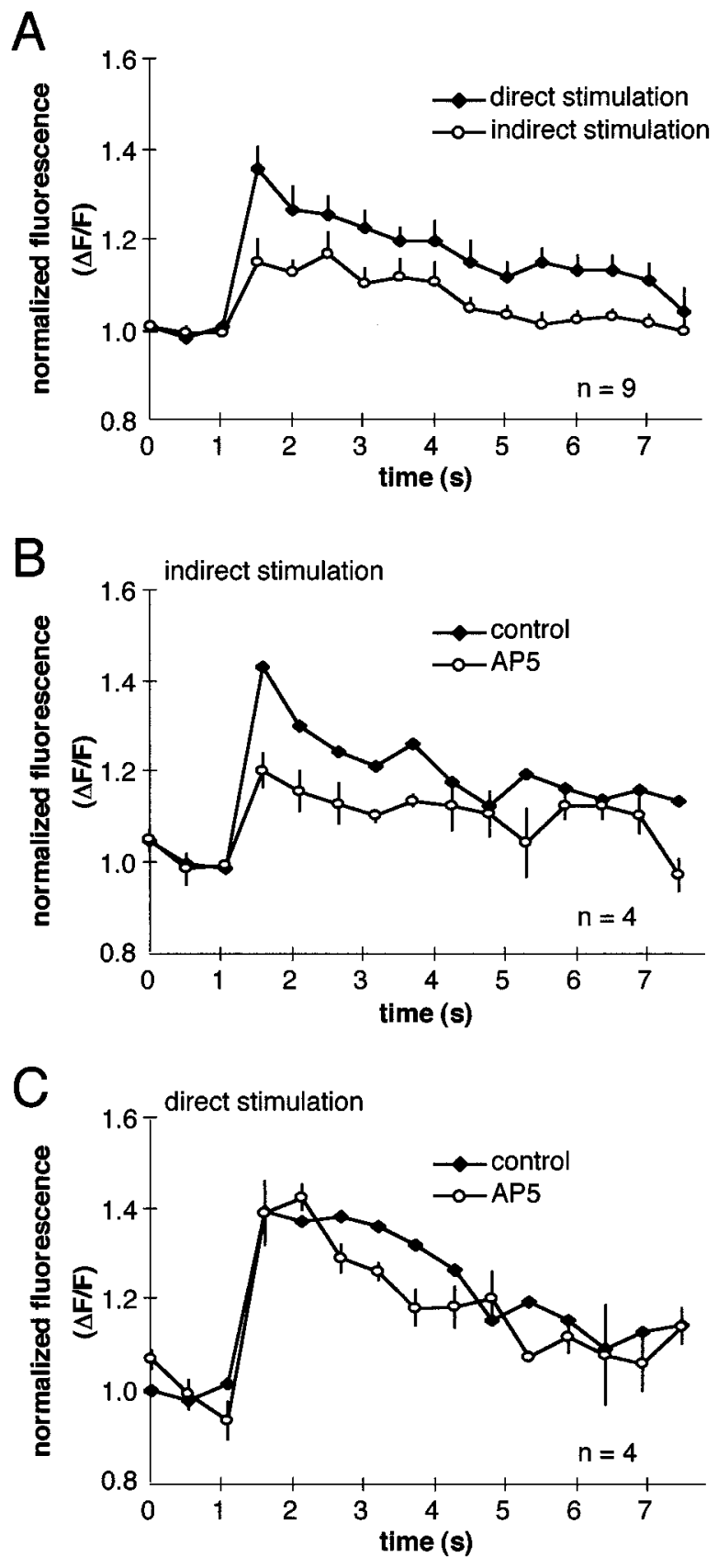

Figure 5. Pooled data comparing $\mathrm{Ca}^{2+}$ transients evoked by direct and indirect stimulation. $A$, Normalized fluorescence recorded in nine axons in response to indirect and direct stimulation. $B$, Normalized fluorescence from four axons in response to indirect stimulation in normal Ringer's solution or in the presence of $A P-5(50 \mu \mathrm{M})$. $C$, Normalized fluorescence from the same four axons in response to direct stimulation recorded in normal Ringer's solution or in the presence of $A P-5(50 \mu \mathrm{M})$. Note that the $\mathrm{Ca}^{2+}$ transient recorded in response to indirect stimulation is sensitive to $A P-5$, whereas the transient recorded in response to direct stimulation is not. Data are expressed as the mean \pm SE. SEs for $B$ and $C$ are calculated relative to the control response.

transient was not sensitive to AP-5 (50 $\mu \mathrm{M}$; AP-5 response amplitude was $98.7 \%$ of control amplitude; $p=0.49$; Figs. $4 C, 5 C$ ). Thus, direct stimulation evokes $\mathrm{Ca}^{2+}$ entry into the axons in an AP-5-insensitive manner, whereas indirect stimulation evokes $\mathrm{Ca}^{2+}$ entry in an AP-5-sensitive manner. Yet, with indirect stimulation there is a response remaining in the presence of
AP-5, indicating that at least some of the indirectly activated $\mathrm{Ca}^{2+}$ entry is through channels other than NMDA channels.

It is possible to extract an approximate change in $\mathrm{Ca}^{2+}$ concentration associated with the fluorescence transients observed. Measurements from standard $\mathrm{Ca}^{2+}$ concentrations using the dextran conjugate of Oregon green 488 BAPTA-1 reveal a $K_{d}$ of $170 \mathrm{nM}$ and a 10-fold increase in fluorescence between $0 \mathrm{mM}$ $\mathrm{Ca}^{2+}$ bound to a saturating concentration of $40 \mu \mathrm{M}\left(F_{\max } / F_{\min }=\right.$ $10)$. Retrogradely labeled axons were permeabilized with ionomycin, and the resultant fluorescence was quenched with $\mathrm{Mn}^{2+}$ or $\mathrm{Co}^{2+}$. The ratio of resting fluorescence to minimum fluorescence $\left(F_{\mathrm{r}} / F_{\min }\right)$ was 4.5 (M. Takahashi and S. Alford, unpublished observation). It is possible to estimate the magnitude of the resting $\mathrm{Ca}^{2+}$ concentration and the value of peak $\mathrm{Ca}^{2+}$ using these parameters and the following equation:

$$
\left[\mathrm{Ca}^{2+}\right]-K_{d} \frac{\left(F-F_{\min }\right)}{\left(F_{\max }-F\right)} .
$$

Given the ratios of $F_{\text {max }} / F_{\text {min }}=10$ and $F_{\mathrm{r}} / F_{\text {min }}=4.5$, we can calculate resting $\left[\mathrm{Ca}^{2+}\right]$ as:

$$
170 n M \frac{\left(4.5 F_{\min }-F_{\min }\right)}{\left(10 F_{\min }-4.5 F_{\min }\right)},
$$

or resting $\left[\mathrm{Ca}^{2+}\right]$ is $108 \mathrm{~nm}$. Similarly the maximum ratio of peak fluorescence to resting fluorescence (Fig. $4 \mathrm{~B}$, inset) is 2.0. Consequently peak $\left[\mathrm{Ca}^{2+}\right]$ is close to saturation of the dye with a ratio $F_{\mathrm{p}} / F_{\text {min }}$ of 9 . This reveals a peak $\left[\mathrm{Ca}^{2+}\right]$ during stimulation of 1.3 $\mu \mathrm{M}$, which is essentially saturating during the application of 10 stimuli. It should be emphasized that these values are approximate. The data for minimum and maximum fluorescence could not be obtained from the axons in which the experiments were performed. This calculation does, however, provide a justification that the NMDA receptor-mediated elevation in $\mathrm{Ca}^{2+}$ is significant. Each stimulus provides a presynaptic rise in $\left[\mathrm{Ca}^{2+}\right]$ of 200 nM or more.

To investigate the time course of $\mathrm{Ca}^{2+}$ entry under more physiological conditions, we used a second method to record the indirect stimulation-evoked $\mathrm{Ca}^{2+}$ transient. A single line of the image over a reticulospinal axon (Fig. 4Di) was chosen for repetitive scanning at $500 \mathrm{~Hz}$. The preparation was bathed in normal saline containing $1.8 \mathrm{mM} \mathrm{MgCl}_{2}$. Indirect stimulation was applied to the spinal cord adjacent to the recorded axon. A single stimulus was applied, and the resulting $\mathrm{Ca}^{2+}$ transient was recorded (Fig. 4Di). AP-5 $(50 \mu \mathrm{M})$ was applied to the superfusate and caused a significant and reversible reduction in the amplitude of the evoked response (amplitude was reduced to $53.2 \pm 10.0 \%$ of control; $n=3$; Fig. 4 Dii). It was not possible to rule out that indirect stimulation causes spiking of the imaged reticulospinal axons, either by synaptic input raising the axonal membrane potential to action potential threshold (Cochilla and Alford, 1997) or by current spread from the stimulating electrode causing a direct stimulation of the axons.

To address this question, we made electrophysiological recordings of the membrane potential of the axons during these experiments (1) to monitor when the axon was firing action potentials versus when it was responding with EPSPs and (2) to stimulate selectively the axon in isolation from other axons. After retrogradely labeling the preparation with OGB-1, a microelectrode was used to record from an axon within the spinal cord that had been retrogradely labeled with $\mathrm{Ca}^{2+}$-sensitive dye (see Fig. $6 \mathrm{~A}$ for schematic of recording arrangement). To locate visually the 

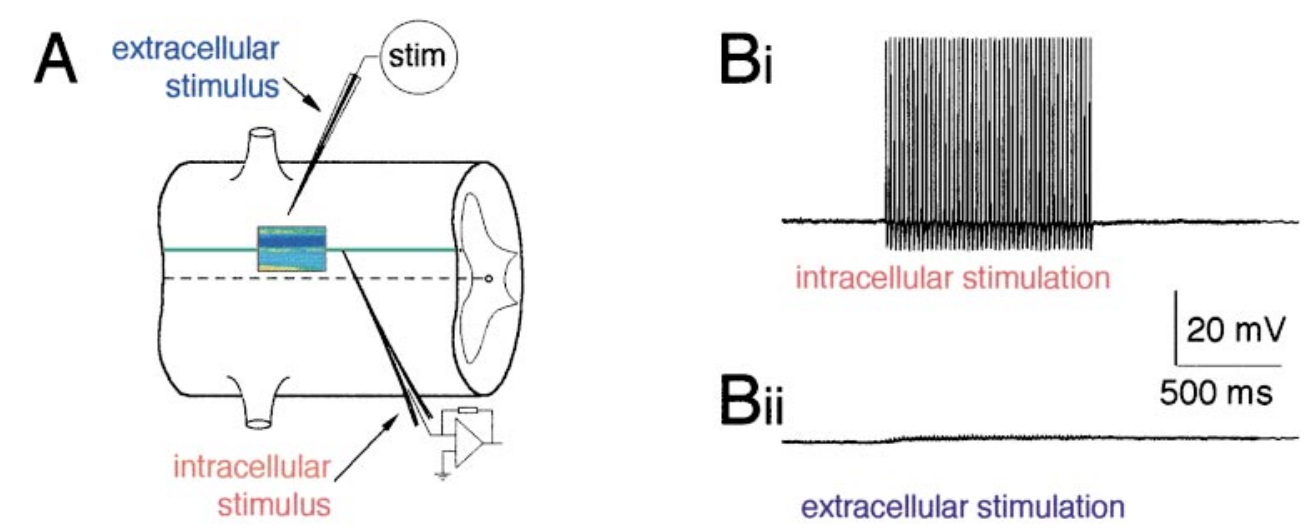

extracellular stimulation
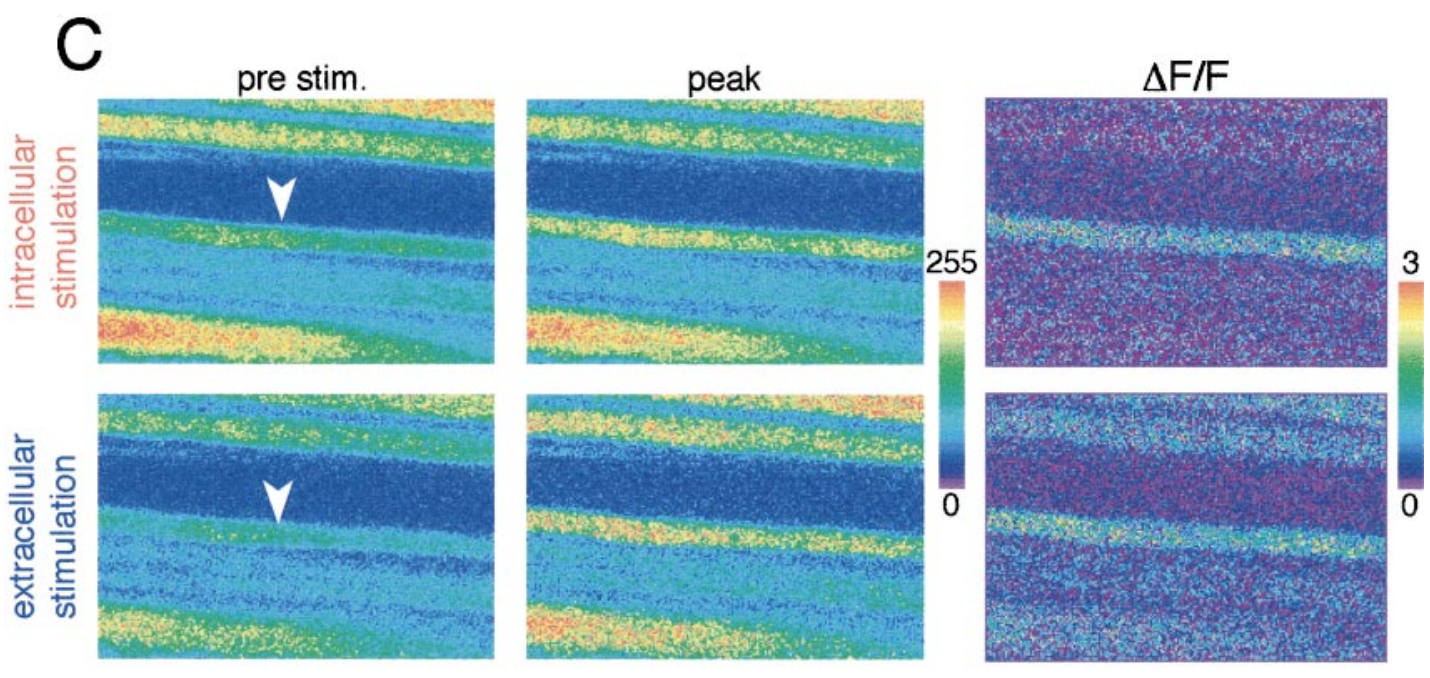

\section{Di extracellular stimulation}

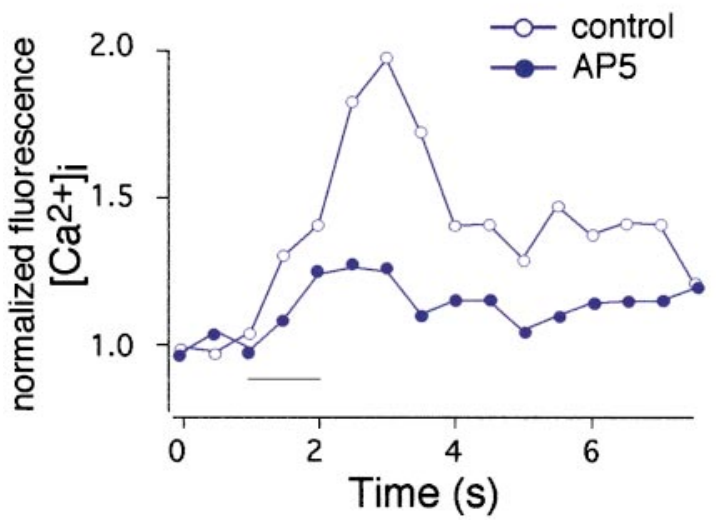

$\mathrm{Dii}$

intracellular stimulation

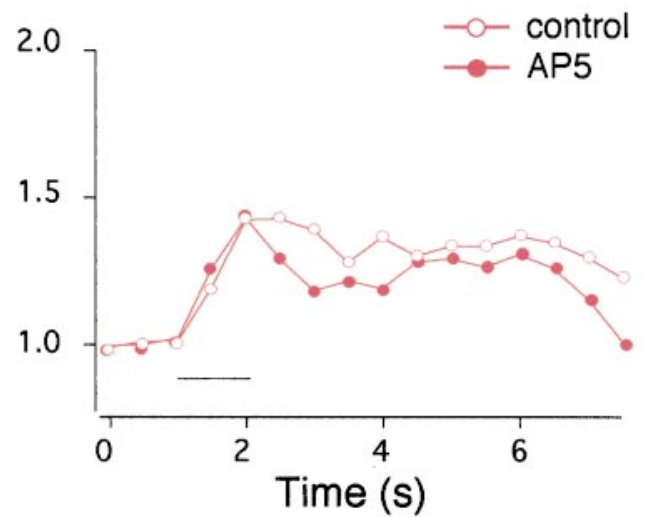

Figure 6. $\mathrm{Ca}^{2+}$ transients evoked by presynaptic action potentials differ from those evoked by EPSPs. $A$, Schematic of recording setup showing a microelectrode recording from an axon and a stimulating electrode positioned to activate reticulospinal axons indirectly, i.e., synaptically. Imaging was performed from the region within the box. $B$, Axonal responses recorded with the microelectrode. The resting potential of the axon was approximately $-70 \mathrm{mV}$. These recordings were made simultaneously to the fluorescence recordings in $C$ and $D$. Stimulus artifacts have been removed for clarity. $B i$, Action potentials recorded in the axon in response to intracellular current injection ( 2 msec current injections at $50 \mathrm{~Hz}$ for $1.0 \mathrm{sec})$. Bii, EPSPs recorded in the axon in response to extracellular stimulation adjacent to the axon $(1 \mathrm{msec}$ shocks at $50 \mathrm{~Hz}$ for $1.0 \mathrm{sec})$. $C$, Images of axonal Ca ${ }^{2+}$ recorded before ( pre stim.) and during ( peak) stimulation. Right, The normalized fluorescence change between the pre stim. and peak conditions. Top row, The response to intracellular stimulation seen in Bi. Bottom row, The response to extracellular stimulation seen in Bii. The microelectrode recording is from the axon marked by the arrowheads. This is the only axon that shows a response to intracellular stimulation as is clear in the normalized image. Each panel is $158 \times$ $106 \mu \mathrm{m}$ in size. $D i$, Normalized fluorescence for the axon recorded by the microelectrode during extracellular stimulation. The axonal fluorescence in response to extracellular stimulation is shown for images recorded before and after addition of $A P-5(50 \mu \mathrm{M})$. Dii, The normalized fluorescence recorded from the same axon in response to intracellular stimulation shown for images recorded before and after addition of $A P-5$ (50 $\mu \mathrm{M})$. 
axon from which recordings were being made, we injected depolarizing current into the axon to elicit action potentials (Fig. 6Bi). The action potentials elicited a $\mathrm{Ca}^{2+}$ transient in the axon. The only axon in the field of view that showed a $\mathrm{Ca}^{2+}$ transient in response to the current injection was the axon from which recordings were being made with the microelectrode (Fig. 6C, Dii). Once the axon was identified, the extracellular stimulating electrode was positioned, and the stimulus strength was adjusted to elicit EPSPs in the axon without evoking action potentials (mean peak EPSP amplitude, $4.2 \pm 0.5 \mathrm{mV}$; reduced to $2.9 \pm 0.6 \mathrm{mV}$ in AP-5; $n=8$; Fig. $6 B i i, C, D i)$. To maximize the NMDA receptormediated response and eliminate other ionotropic glutamate receptor-mediated responses, these experiments were performed in $\mathrm{Mg}^{2+}$-free superfusate and in the presence of CNQX $(10 \mu \mathrm{M})$. The amplitude of the $\mathrm{Ca}^{2+}$ transient elicited by EPSPs was $25.4 \pm 4.01 \%$ of the amplitude of the $\mathrm{Ca}^{2+}$ transient evoked by action potentials $(~ p<0.005 ; n=8)$. The EPSP-mediated $\mathrm{Ca}^{2+}$ transient was sensitive to AP-5. The amplitude of the $\mathrm{Ca}^{2+}$ transient evoked by extracellular stimulation in the presence of AP-5 $(50 \mu \mathrm{M})$ was reduced to $3.0 \pm 1.9 \%$ of the control response $(p<0.05 ; n=4$; Fig. $6 \mathrm{Di})$. The action potential-mediated $\mathrm{Ca}^{2+}$ transient was not sensitive to AP-5 $(50 \mu \mathrm{M})$ and was $105.8 \pm 5.7 \%$ of the control response ( $p=0.43 ; n=4$; Fig. 6 Dii). From these experiments we conclude that during axoaxonic EPSPs, $\mathrm{Ca}^{2+}$ enters the presynaptic element through NMDA channels in response to an excitatory synaptic input that impinges directly on the axon.

\section{Activation of presynaptic NMDA receptors changes axonal failure rate}

NMDA receptor-mediated $\mathrm{Ca}^{2+}$ entry might have the ability to alter transmitter release from reticulospinal axons at their synapses onto motoneurons. However, it was not possible to test directly the effect of NMDA application on the amplitude of neurotransmitter release from those axons because the postsynaptic targets also possess NMDA receptors and activation of these receptors leads to complex activity in the spinal cord (Brodin et al., 1985). Synaptically activated inputs to the axons could provide a transient input to the axons leading to $\mathrm{Ca}^{2+}$ entry via NMDA receptors. This $\mathrm{Ca}^{2+}$ transient can last for seconds after the stimulus (see Fig. 3). We wished to test the hypothesis that axo-axonic synaptically mediated $\mathrm{Ca}^{2+}$ entry into the axons was able to modulate glutamate release from these axons. To test this hypothesis it was necessary to activate the synaptic input to the axon while monitoring the synaptic efficacy of the output synapses of the axons. To perform these experiments we made paired recordings from a presynaptic axon and a synaptically coupled postsynaptic motoneuron. The axon was held under current clamp with a microelectrode. This allowed us both to monitor the membrane potential during extracellular stimulation to ensure that the axons did not spike and to generate spikes in the axon directly by current injection. The motoneuron was held under voltage clamp with a patch electrode. The recording arrangement is illustrated schematically in Figure $7 A$.

The presynaptic axon was stimulated by passing brief depolarizing current pulses to evoke action potentials. EPSCs were then recorded in the postsynaptic neuron (Fig. $7 B$ ). The extracellular stimulating electrode was then used to apply a prepulse stimulus to the spinal cord $100 \mathrm{msec}$ before the direct stimulation of the axon through the recording microelectrode. The prepulse stimulus amplitude was always set low enough to ensure that it did not evoke an action potential in the presynaptic axon. The amplitude
A
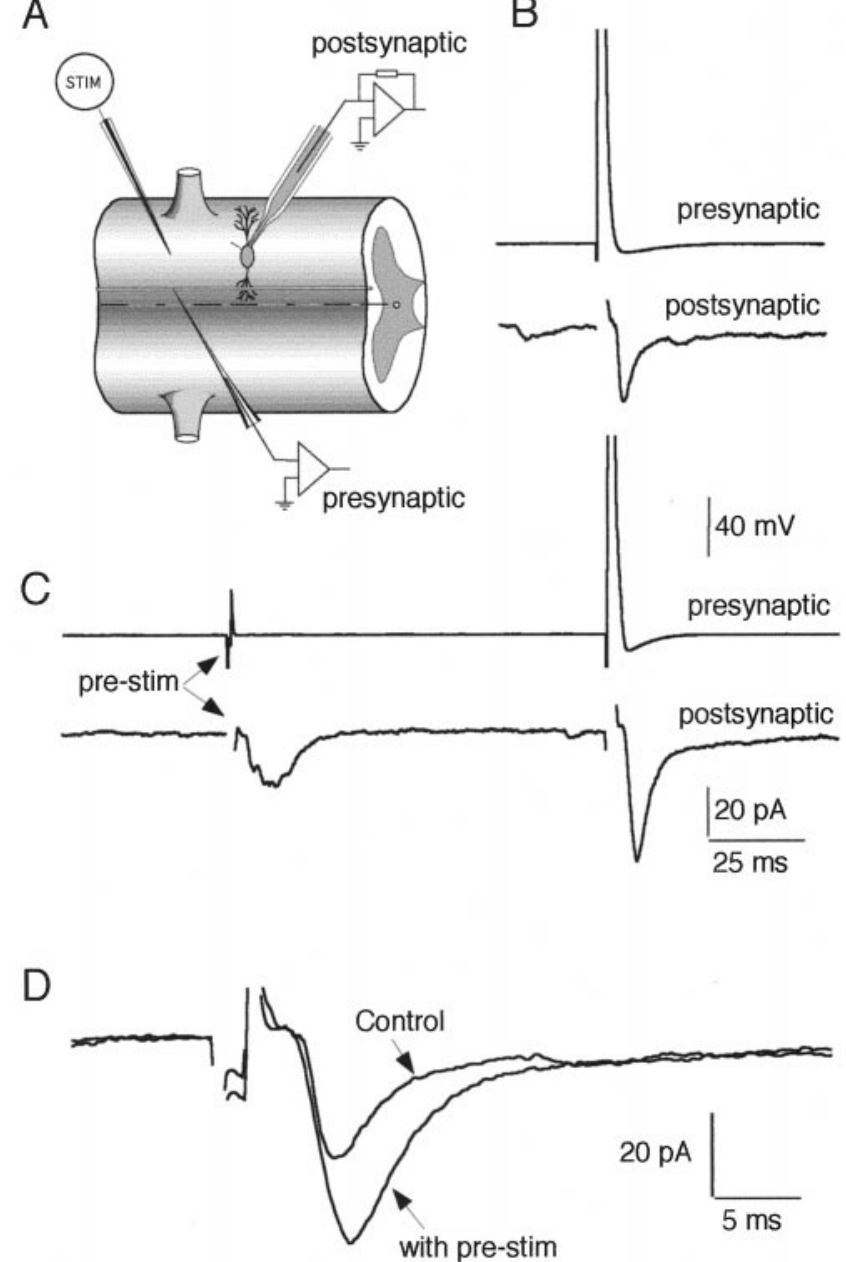

Figure 7. Activation of synaptic input to reticulospinal axon facilitates transmission from reticulospinal axon to motoneuron. A paired recording was made between a presynaptic reticulospinal axon and a postsynaptic motoneuron. The axon was held under current clamp with a microelectrode, and the motoneuron was held under voltage clamp with a patch electrode. $A$, Schematic to describe the recording arrangement. The prestimulus was provided via an extracellular stimulating electrode placed lateral to the recorded pair. $B$, The firing of an action potential by an axon in response to a brief $(2 \mathrm{msec})$ depolarizing current injection (top). This evoked an EPSC in the postsynaptic motoneuron (bottom). $C$, Recordings from the same pair of neurons shown in $B$. Before current was injected to elicit an action potential in the axon, the spinal cord was stimulated to elicit an EPSP in the axon (prestim). This stimulation also elicited EPSCs in the postsynaptic neuron. After the prestimulus, current was injected into the axon to elicit an action potential and a resulting EPSC in the postsynaptic neuron. $D$, Enlargement of the postsynaptic response to the presynaptic action potential before and after the application of a prestimulus. The response is clearly enhanced by the prestimulus. All traces are averages of four sequential responses.

of postsynaptic EPSCs evoked by direct stimulation of the axon in the absence of a prestimulus was compared with the amplitude of EPSCs that were evoked in the presence of an extracellular prestimulus. In seven pairs tested, the amplitude of the postsynaptic EPSC was augmented when the presynaptic prestimulus was given (amplitude increased to $133.1 \pm 13.5 \%$ of control; $p<0.05)$.

It is reasonable to hypothesize that the enhancement of the synaptic response was mediated by a presynaptic action of the prestimulus. It was difficult, however, to determine this directly 


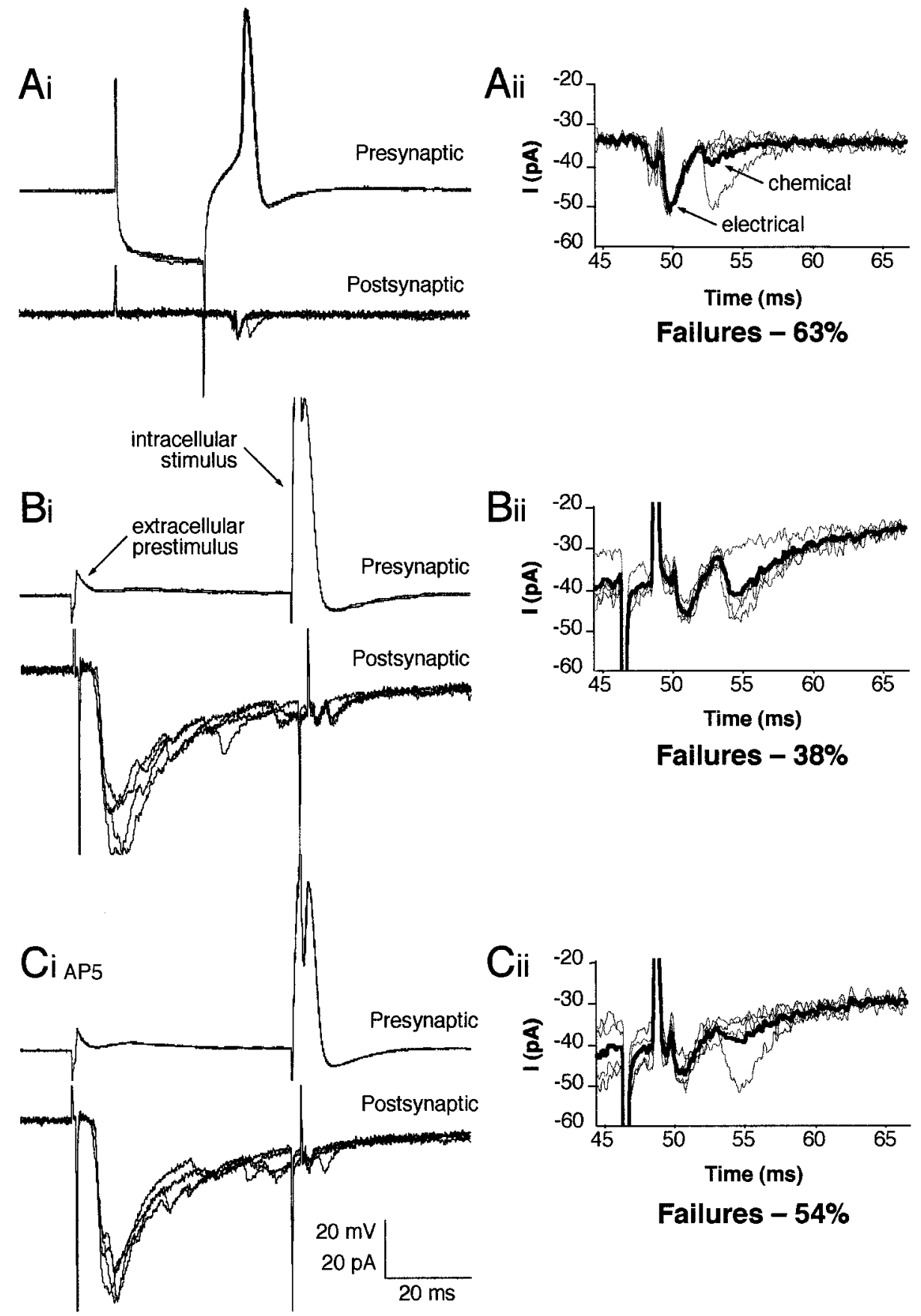

Figure 8. Activation of synaptic input to reticulospinal axon facilitates transmission from reticulospinal axon to motoneuron. $A$, A paired recording made between a presynaptic reticulospinal axon and a postsynaptic motoneuron (as in Fig. 7). The axon was held under current clamp with a microelectrode, and the motoneuron was held under voltage clamp with a patch electrode. $A i$, Action potential evoked in the axon in response to current injection (top). The motoneuron responds to the presynaptic action potential with a mixed chemical and electrical EPSC (bottom). Aii, Enlargement of the responses of the postsynaptic neuron to the presynaptic action potentials. Individual traces are shown in gray, and the average of the four traces is shown in black. There is a failure rate of $63 \%$ for the chemical component. $B i$, Recordings from the same pair of neurons shown in $A$. Before current was injected to elicit an action potential in the axon (intracellular stimulus), the spinal cord was stimulated to elicit an EPSP in the axon (extracellular prestimulus). This stimulation also elicited EPSCs in the postsynaptic neuron. After the prestimulus, current was injected into the axon to elicit an action potential in the axon and a resulting EPSC in the postsynaptic neuron as described for Figure 7. Bii, Enlargement of the responses of the postsynaptic neuron to the presynaptic action potentials. The failure rate of the EPSCs elicited after the prestimulus is now $38 \%$. $\mathrm{Ci}$, The same protocol described in $B i$ performed in the presence of $A P-5(50 \mu \mathrm{M})$. Cii, Enlargement of the responses of the postsynaptic neuron to the presynaptic action potentials. The failure rate of the EPSCs elicited after the prestimulus in the presence of $A P-5$ is increased to $54 \%$. from the amplitude of the postsynaptic response. Failure rates of chemical synaptic transmission were, therefore, analyzed in two of the recorded pairs in which the failure rate of the chemical component of the synaptic response was $>30 \%$. Presynaptic action potentials elicited mixed chemical and electrical EPSCs in the postsynaptic neurons (Fig. 8Ai, Aii). The chemical component of the EPSCs showed variations in amplitude to sequential stimuli; however, the amplitude of the electrical component remained constant (Fig. 8Aii). Monitoring the amplitude of the electrical component of the postsynaptic response during stimulation served as a good measure of presynaptic action potential propagation. If the electrical component was not recorded, then the presynaptic action potential was not consistently propagating to the synaptic contact between the axon and the motoneuron, and the data were subsequently excluded from analysis. In the example shown in Figure 8, the number of failures was decreased when the extracellular prestimulus was activated $(63 \%$ failure rate without the prestimulus; $38 \%$ failure rate with the prestimulus). The decrease in failure rate was blocked by AP-5 (50 $\mu \mathrm{M} ; 54 \%$ failure rate with the prestimulus in AP-5).

The data for this cell are summarized in Figure 9. The panels follow the same sequence as those of Figure 8. Amplitude histograms are displayed showing the marked reduction in failures of chemical transmission after the application of a prestimulus. The amplitude histogram of the electrical component of the synaptic response demonstrates that the presynaptic action potential always invaded the terminal. In the two axons analyzed for failures, an electrical component of the synaptic response was always 

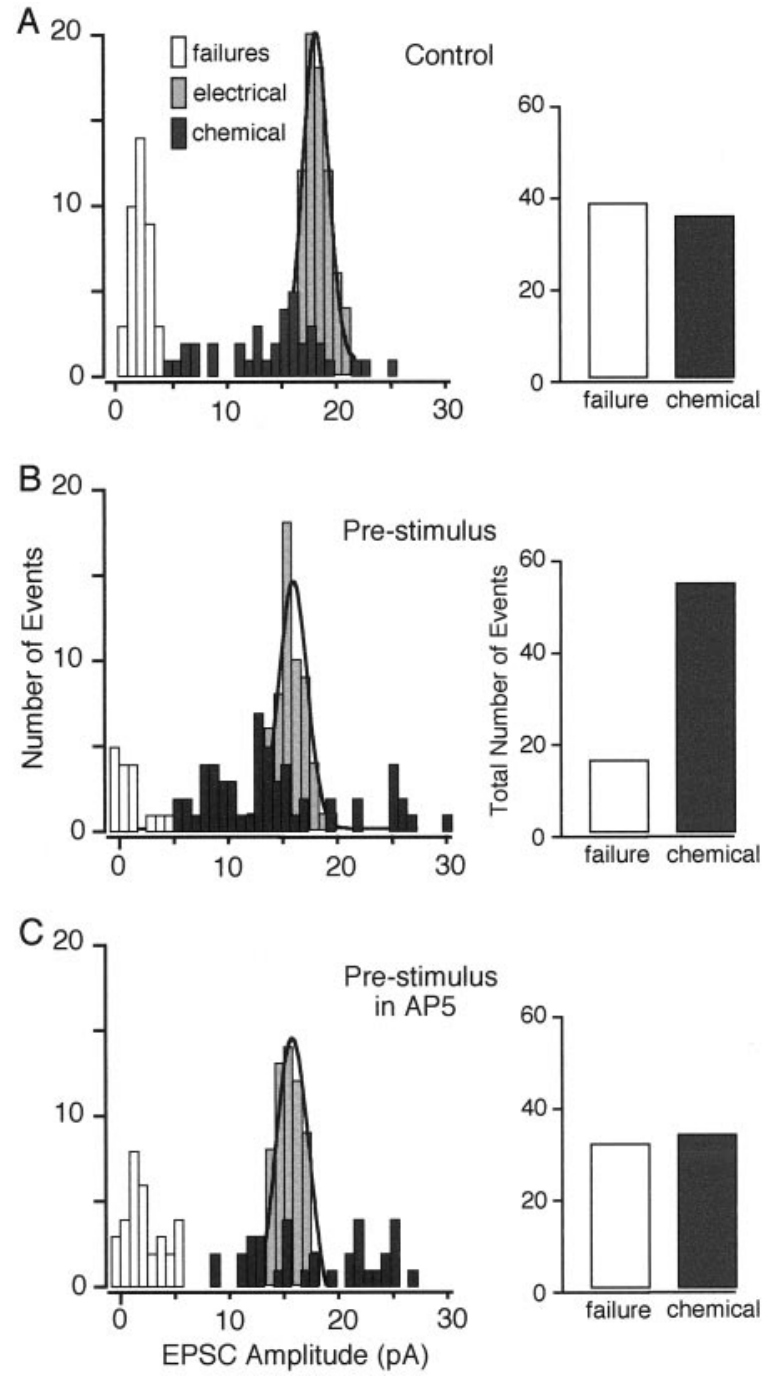

Figure 9. Amplitude histograms of paired synaptic responses between a reticulospinal axon and a postsynaptic neuron. This data are from the pair of neurons illustrated in Figure 8. A, The EPSC amplitudes recorded after stimulation of only the presynaptic reticulospinal neuron. Left, A histogram of all event amplitudes. Those events marked in white were considered failures. Events marked gray were amplitudes of individual electrical events, in which the amplitude histogram showed a similar distribution to the recording noise. The black events were identified as chemical events. No event was included (either electrical or chemical) if there was no preceding electrical event. Right, Comparison of the rate of failures with the existence of a chemical response regardless of the amplitude of the chemical response. $B$, The EPSC amplitudes recorded on stimulation of the reticulospinal axon $100 \mathrm{msec}$ after the application of a prepulse to the spinal cord. The panels are as described for $A$. The application of a prepulse markedly reduced the number of recorded failures. Note that the mean amplitude of the electrical component was slightly reduced. This effect reflects the synaptic drive from the prepulse on the postsynaptic neuron. $C$, EPSC amplitudes recorded similarly to $B$ but after the addition of $A P-5(100 \mu \mathrm{M})$.

present. The reduction of failure frequency by the prestimulus in an AP-5-dependent manner is consistent with the presynaptic activation of NMDA receptors that enhance the probability of neurotransmitter release.

\section{DISCUSSION}

Whole-cell patch recordings in giant axons of the lamprey have revealed individual synaptic inputs to the axons. Functionally, such recordings are electrically equivalent to recording from the presynaptic terminal. These axons possess no arborization and are known to form en passant glutamatergic synapses with motoneurons and interneurons along the entire length of the spinal cord (Rovainen, 1974; Shupliakov et al., 1992). Stimulation of the spinal cord lateral to the ventromedial tracts where the reticulospinal axons are located evokes a depolarization in the axons that is mediated by excitatory synapses impinging on the axon (see Fig. 1). The depolarization is mediated by glutamate acting at both AMPA and NMDA receptors (Cochilla and Alford, 1997). It has become clear that ionotropic glutamate receptors are present in mammalian presynaptic terminals (Agrawal and Evans, 1986; Barnes et al., 1994; Farb et al., 1995; Smirnova et al., 1993; Berretta and Jones, 1996; Dev et al., 1996; Aoki et al., 1997; Clarke et al., 1997; Conti et al., 1997; Liu et al., 1997). Yet, very little is understood of the effect of activation of these receptors on release of transmitter. Our goal was to determine whether $\mathrm{Ca}^{2+}$ entered the axons through the NMDA receptors and, if so, whether the $\mathrm{Ca}^{2+}$ entry could alter neurotransmitter release from the axon.

After wash-in of NMDA into the preparation, $\mathrm{a} \mathrm{Ca}^{2+}$ transient is visible in the axons (see Fig. 2). This $\mathrm{Ca}^{2+}$ entry is not attributable to $\mathrm{Ca}^{2+}$ entry through voltage-operated $\mathrm{Ca}^{2+}$ channels. Application of NMDA to the preparation after blockade of $\mathrm{Na}^{+}$channels with TTX does not cause significant depolarization of the axons (see Fig. 3) (Cochilla and Alford, 1997). We have shown previously (Cochilla and Alford, 1998) that these axons do not possess any low voltage-activated $\mathrm{Ca}^{2+}$ channels; voltageoperated $\mathrm{Ca}^{2+}$ channels are not activated until the membrane is stepped to potentials more positive than $-40 \mathrm{mV}$. Because the superfusion of NMDA will only depolarize the membrane by $\sim 5$ $\mathrm{mV}$ and because there are no low voltage-activated voltageoperated $\mathrm{Ca}^{2+}$ channels on these axons, we can conclude that $\mathrm{Ca}^{2+}$ transients elicited by NMDA wash-in in the presence of TTX are attributable to $\mathrm{Ca}^{2+}$ entry through NMDA channels located on the axonal membrane.

$\mathrm{Ca}^{2+}$ entry into the axons can also be evoked by stimulating the spinal cord lateral to the axon tracts (see Fig. 3). The sensitivity of this transient to both $\mathrm{Mg}^{2+}$ and AP-5 is indicative of NMDA receptor-mediated responses (Mayer et al., 1984; Nowak et al., 1984). $\mathrm{Ca}^{2+}$ transients are also initiated by direct axonal stimulation (see Fig. 4). However, these $\mathrm{Ca}^{2+}$ transients are qualitatively different from the transients evoked by indirect stimulation. Transients evoked by indirect stimulation are sensitive to AP-5 and are smaller in amplitude than $\mathrm{Ca}^{2+}$ transients evoked by direct axonal stimulation. Direct electrophysiological recordings from axons during $\mathrm{Ca}^{2+}$-imaging experiments allowed us to show definitively that $\mathrm{Ca}^{2+}$ enters the presynaptic element during EPSPs evoked in the axon that are subthreshold to the activation of voltage-operated $\mathrm{Ca}^{2+}$ channels (see Fig. 6). Similar to $\mathrm{Ca}^{2+}$ entry mediated by application of NMDA to the preparation, the depolarizations activated by synaptic inputs onto the axons $(\sim 5 \mathrm{mV}$ from a resting membrane potential of $-70 \mathrm{mV}$; see Fig. $6 \mathrm{Bi}$ ) are not large enough to activate VOCCs.

The location of the NMDA receptor-mediated $\mathrm{Ca}^{2+}$ transient in reticulospinal axons is important in the determination of whether the elevated $\mathrm{Ca}^{2+}$ concentration will alter evokedtransmitter release from the axons. For the NMDA receptordependent axonal $\mathrm{Ca}^{2+}$ transients demonstrated in the reticulospinal neurons to alter evoked-transmitter release from the axons, it is clear that the elevated $\mathrm{Ca}^{2+}$ must be present at or near the presynaptic specializations of the reticulospinal axons. Re- 

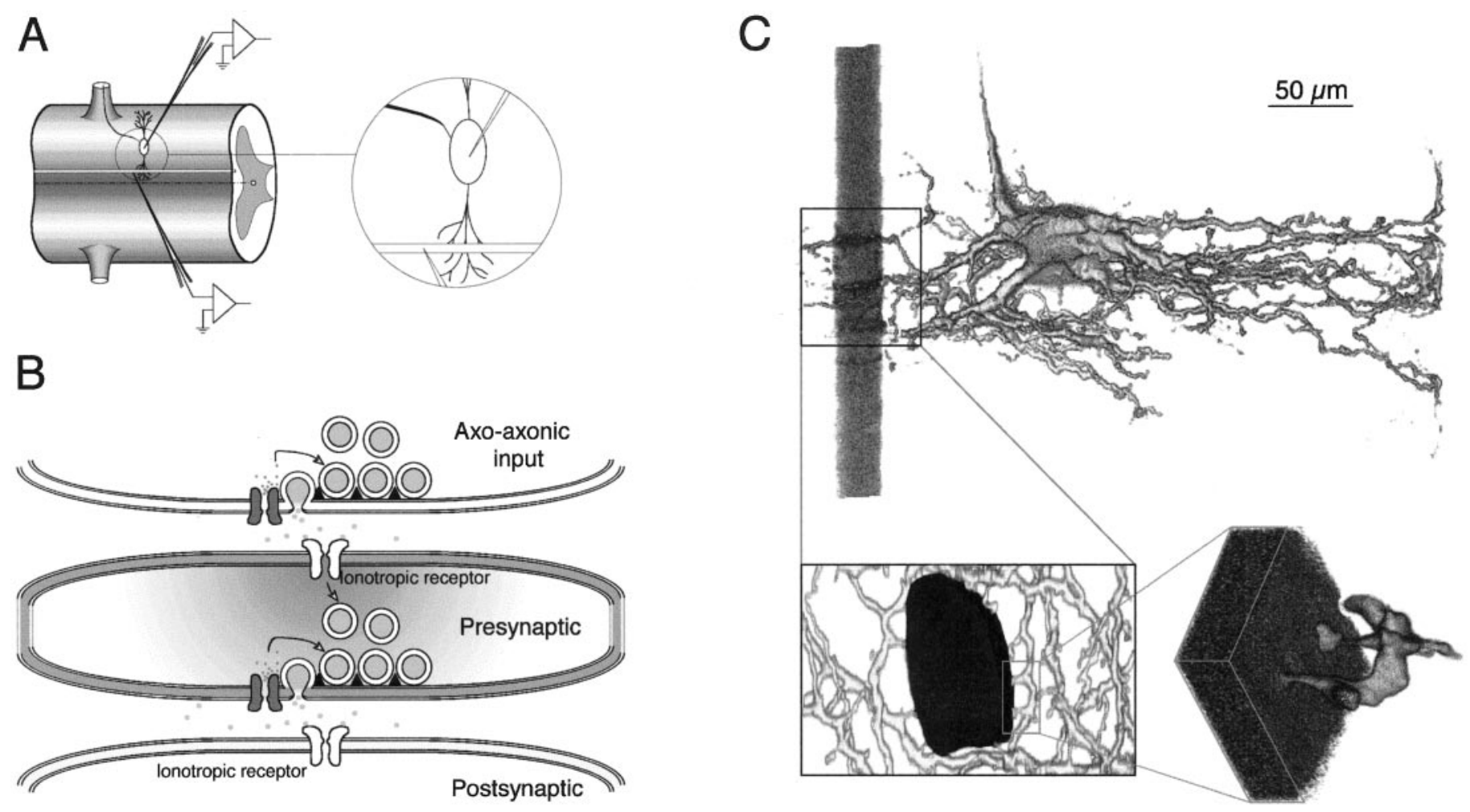

Figure 10. Model explaining the mechanism of presynaptic NMDA receptor enhancement of transmitter release. $A$, Schematic demonstrating the relationship between reticulospinal neurons and their postsynaptic targets. The electrodes shown represent the approximate placement of electrodes used to fill the neurons for the image in $C$. B, The axoaxonic input to the reticulospinal neuron activating ionotropic glutamate receptors, including NMDA receptors, on the presynaptic reticulospinal axon (blue). This causes a wide diff usion of $\mathrm{Ca}^{2+}$ in the axon $($ red $)$. The extent of the Ca ${ }^{2+}$ signal can be $>500 \mu \mathrm{m}$ along the axon (as demonstrated in Fig. 6). This $\mathrm{Ca}^{2+}$ transient will alter the basal $\mathrm{Ca}^{2+}$ concentration at numerous synaptic terminals. In the schematic, the region of elevated calcium encompasses glutamatergic vesicles and $\mathrm{Ca}^{2+}$ channels, and there is an enhancement of transmission onto postsynaptic neurons. $C$, Three-dimensional reconstruction of a synaptically coupled reticulospinal axon (dark vertical structure) and postsynaptic premotor interneuron. The pair was identified electrophysiologically using paired-microelectrode recording between the two cells as shown in the schematic in $A$. Both cells were filled with fluorescent dye (Lucifer yellow) by pressure ejection through the microelectrodes. Images were obtained using a confocal microscope. The boxed region of the top is enlarged and rotated $90^{\circ}$ on the bottom left, to view along the long axis of the axon. On the bottom right, two individual synaptic contacts (boxed region of the bottom left) are shown rotated at high magnification for improved visualization. This image demonstrates the relationship between the structure of the axons and the location of the en passant synaptic terminals. Each axon makes many overlapping synaptic contacts similar to the contact shown. Thus, an axoaxonically evoked $\mathrm{Ca}^{2+}$ rise that diffuses hundreds of micrometers along the axon will affect $\mathrm{Ca}^{2+}$ concentrations at numerous presynaptic terminals in the reticulospinal axon.

ticulospinal axons of the lamprey spinal cord show numerous en passant synaptic connections at all segmental levels in the spinal cord (Rovainen, 1974), such that motoneuronal dendrites surround the axons (see Fig. 10).

To illustrate the relationship between synaptically evoked presynaptic $\mathrm{Ca}^{2+}$ entry, the presynaptic axon, and the location of the output synapses from that axon, we made paired-cell recordings to label and image reticulospinal axons and their postsynaptic target neurons. The recording arrangement is shown in the schematic of Figure $10 A$. To affect release from the axon, $\mathrm{Ca}^{2+}$ entering the axon through synaptic NMDA receptors must be within close proximity to the release sites of the axon. The hypothesis is illustrated in the schematic in Figure $10 \mathrm{~B}$. That this scheme is possible is illustrated by the reconstruction of the reticulospinal axon and its postsynaptic target in Figure $10 C$. The $\mathrm{Ca}^{2+}$ transients illustrated in Figures 4 and 6 clearly encompass a volume of axon that would contain numerous presynaptic sites (for the axon shown in Fig. 4, $75 \mu \mathrm{m}$ of axon is affected by the stimulus). Additionally, the $\mathrm{Ca}^{2+}$ transients recorded in response to action potential initiation in the axon and to synaptic stimulation of inputs to the axon show considerable overlap (see Fig. 6).

Activation of excitatory axo-axonic synapses onto reticulospi- nal axons enhances release from the axons. The mixed electrical and chemical synapse between reticulospinal axons and motoneurons provides a built-in control for determining whether the action potential has propagated to the synapse. The electrical component of the response was not blocked by previous activation of the axoaxonic synaptic input. Neither did application of AP-5 affect the electrical component. However, the chemical component was markedly enhanced by previous activation of the extracellular prestimulus and subsequently depressed by application of AP-5 (see Fig. 7). This enhancement is a presynaptic phenomenon. Failure of the axon to release neurotransmitter causes failures in the chemical component of a synaptic response. The failure rate of the reticulospinal axon was reduced when the axoaxonic synapse impinging on the axon was stimulated (see Figs. 8, 9). When NMDA receptors were blocked by AP-5, the depression of the failure rate was blocked.

A number of mechanisms may account for the stimulus- and NMDA receptor-dependent enhancement seen in this study. (1) Evoked axonal NMDA receptor activation will depolarize the presynaptic axon. This may lead to a greater activation of $\mathrm{Ca}^{2+}$ channels when action potentials are evoked in the presynaptic axon. (2) Alternatively, activation of presynaptic NMDA recep- 
tors may lead to a presynaptic second messenger cascade after $\mathrm{Ca}^{2+}$ entry via these NMDA receptors. (3) Finally, this effect may be caused by $\mathrm{Ca}^{2+}$ entry into the presynaptic element through synaptic NMDA channels acting at the presynaptic release sites.

We propose that the simplest explanation is found in the third mechanism. Activation of the axo-axonic synapse elicits EPSPs in the axon that stimulate NMDA receptors and cause $\mathrm{Ca}^{2+}$ entry into the presynaptic element. After only one stimulus, axonal $\mathrm{Ca}^{2+}$ levels had not returned to baseline levels after 1 sec (see Fig. 4). Thus, a localized area of elevated baseline $\mathrm{Ca}^{2+}$ would exist within the axon for seconds after activation of the synaptic input to the axon. Any output synapse within that localized area would be affected by the elevated $\mathrm{Ca}^{2+}$ that reaches at least hundreds of nanomolar above resting levels with just one stimulus. Activation of synaptic inputs to these axons thereby facilitates release from the axon. $\mathrm{Ca}^{2+}$ enters the presynaptic element through synaptic NMDA receptors located on the axon and diff uses to nearby output synapses where it enhances neurotransmitter release from those synapses. This enhancement occurs in a manner similar to one mechanism that is proposed to underlie paired-pulse facilitation (Katz and Miledi, 1968; Kamiya and Zucker, 1994; Bertram, 1997). If the axon fires an action potential within a short time after receiving the synaptic input or if the synaptic input drives the axon to fire an action potential (Cochilla and Alford, 1997), neurotransmitter release from the axon would be enhanced at output synapses near the input synapse. In principle, the same mechanism of presynaptic $\mathrm{Ca}^{2+}$-induced facilitation of transmitter release would occur if the NMDA receptors were also positioned as autoreceptors at the reticulospinal synaptic terminal. We are not, at this time, able to test this hypothesis directly. However, NMDA receptors thus far identified in mammalian synaptic terminals have been proposed to be autoreceptors.

\section{REFERENCES}

Agrawal SG, Evans RH (1986) The primary afferent depolarizing action of kainate in the rat. Br J Pharmacol 87:345-355.

Alford S, Dubuc R (1993) Glutamate metabotropic receptor-mediated depression of synaptic inputs to lamprey reticulospinal neurons. Brain Res 605:175-180.

Aoki C, Rhee J, Lubin M, Dawson TM (1997) NMDA-R1 subunit of the cerebral cortex co-localizes with neuronal nitric oxide synthase at preand postsynaptic sites and in spines. Brain Res 750:25-40.

Barnes JM, Dev KK, Henley JM (1994) Cyclothiazide unmasks AMPAevoked stimulation of $\left[{ }^{3} \mathrm{H}\right]$-L-glutamate release from rat hippocampal synaptosomes. Br J Pharmacol 113:339-341.

Berretta N, Jones RS (1996) Tonic facilitation of glutamate release by presynaptic $N$-methyl-D-aspartate autoreceptors in the entorhinal cortex. Neuroscience 75:339-344.

Bertram R (1997) A simple model of transmitter release and facilitation. Neural Comput 9:515-523.

Blanton MG, Lo Turco JJ, Kriegstein AR (1989) Whole cell recording from neurons in slices of reptilian and mammalian cerebral cortex. J Neurosci Methods 30:203-210.

Bliss TVP, Collingridge GL (1993) A synaptic model of memory: longterm potentiation in the hippocampus. Nature 361:31-39.

Bliss TVP, Lømo T (1973) Long-lasting potentiation of synaptic transmission in the dentate area of the anaesthetised rabbit. J Physiol (Lond) 232:331-356.

Brodin L, Grillner S, Rovainen CM (1985) N-methyl-D-aspartate (NMDA), kainate and quisqualate receptors and the generation of fictive locomotion in the lamprey spinal cord. Brain Res 325:302-306.
Brodin L, Grillner S, Dubuc R, Ohta Y, Kasicki S, Hokfelt T (1988) Reticulospinal neurones in lamprey: transmitters, synaptic interactions and their role during locomotion. Arch Ital Biol 126:317-345.

Bureau I, Mulle C (1998) Potentiation of GABAergic synaptic transmission by AMPA receptors in mouse cerebellar stellate cells: changes during development. J Physiol (Lond) 509:817-831.

Carlton SM, Chung K, Ding Z, Coggeshall RE (1998) Glutamate receptors on postganglionic sympathetic axons. Neuroscience 83:601-605.

Chen YH, Wu ML, Fu WM (1998) Regulation of presynaptic NMDA responses by external and intracellular $\mathrm{pH}$ changes at developing neuromuscular synapses. J Neurosci 18:2982-2990.

Clarke VRJ, Ballyk BA, Hoo KH, Mandelzys A, Pellizzari A, Bath CP, Thomas J, Sharpe EF, Davies CH, Ornstein PL, Schoepp DD, Kamboj RK, Collingridge GL, Lodge D, Bleakman D (1997) A hippocampal GluR5 kainate receptor regulating inhibitory synaptic transmission. Nature 389:599-603.

Cochilla AJ, Alford S (1997) Glutamate receptor-mediated synaptic excitation in axons of the lamprey. J Physiol (Lond) 499:443-457.

Cochilla AJ, Alford S (1998) Metabotropic glutamate receptormediated control of neurotransmitter release. Neuron 20:1007-1016.

Conti F, Minelli A, Debiasi S, Melone M (1997) Neuronal and glial localization of NMDA receptors in the cerebral cortex. Mol Neurobiol 14:1-18.

Delaney KR, Tank DW (1994) A quantitative measurement of the dependence of short-term synaptic enhancement on presynaptic residual calcium. J Neurosci 14:5885-5902.

Dev KK, Barnes JM, Collingridge GL, Henley JM (1996) Regulation of glutamate release by presynaptic kainate receptors in the hippocampus. Nature 379:78-81.

Ekerot C-F, Kano M (1985) Long-term depression of parallel fibre synapses following stimulation of climbing fibres. Brain Res 342:357-360.

Farb CR, Aoki C, LeDoux JE (1995) Differential localization of NMDA and AMPA receptor subunits in the lateral and basal nuclei of the amygdala: a light and electron microscopic study. J Comp Neurol 362:86-108.

$\mathrm{Fu}$ W-M, Huang FL (1994) L-type $\mathrm{Ca}^{2+}$ channel is involved in the regulation of spontaneous transmitter release at developing neuromuscular synapses. Neuroscience 58:131-140.

Gray R, Rajan AS, Radcliffe KA, Yakehiro M, Dani JA (1996) Hippocampal synaptic transmission enhanced by low concentrations of nicotine. Nature 383:713-716.

Holt AJ, Schwartz NE, Alford S (1996) Presynaptic NMDA receptors control presynaptic calcium. Soc Neurosci Abstr 22:494.

Huang CC, Hsu KS, Gean PW (1996) Isoproterenol potentiates synaptic transmission primarily by enhancing presynaptic calcium influx via $\mathrm{P}$ and/or Q-type calcium channels in the rat amygdala. J Neurosci 16:1026-1033.

Ito M (1989) Long-term depression. Annu Rev Neurosci 12:85-102.

Kamiya H, Ozua S (1998) Kainate receptor-mediated inhibition of presynaptic $\mathrm{Ca}^{2+}$ influx and EPSPs in area CA1 of the rat hippocampus. J Physiol (Lond) 509:817-831.

Kamiya H, Zucker RS (1994) Residual $\mathrm{Ca}^{2+}$ and short-term synaptic plasticity. Nature 371:603-606.

Katz B, Miledi R (1968) The role of calcium in neuromuscular facilitation. J Physiol (Lond) 195:481-492.

Kobayashi K, Sakaba T, Tachibana M (1995) Potentiation of $\mathrm{Ca}^{2+}$ transients in the presynaptic terminals of goldfish retinal bipolar cells. J Physiol (Lond) 482:7-13.

Liu H, Mantyh PW, Basbaum AI (1997) NMDA-receptor regulation of substance $P$ release from primary afferent nociceptors. Nature 386:721-724.

MacDermott AB, Mayer ML, Westbrook GL, Smith SJ, Barker JL (1986) NMDA-receptor activation increases cytoplasmic calcium concentration in cultured spinal cord neurones. Nature 321:519-522.

Mayer ML, Westbrook GL, Guthrie PB (1984) Voltage-dependent block by $\mathrm{Mg}^{2+}$ of NMDA responses in spinal cord neurones. Nature 309:261-263.

Mulkey RM, Zucker RS (1992) Posttetanic potentiation at the crayfish neuromuscular junction is dependent on both intracellular calcium and sodium ion accumulation. J Neurosci 12:4327-4336.

Nowak L, Bregetovski P, Ascher P, Herbet A, Prochiautz A (1984) Magnesium gates glutamate activated channels in mouse central neurons. Nature 307:462-465. 
Ringham GL (1975) Localization and electrical characteristics of a giant synapse in the spinal cord of the lamprey. J Physiol (Lond) 251:395-407.

Robert A, Black JA, Waxman SG (1998) Endogenous NMDA-receptor activation regulates glutamate release in cultured spinal neurons. J Neurophysiol 80:196-208.

Rovainen CM (1974) Synaptic interactions of identified nerve cells in the spinal cord of the sea lamprey. J Comp Neurol 154:189-206.

Sabatini BL, Regehr WG (1995) Detecting changes in calcium influx which contribute to synaptic modulation in mammalian brain slice. Neuropharmacology 34:1453-1467.

Sabria J, Pastor C, Clos MV, Garcia A, Badia A (1995) Involvement of different types of voltage-sensitive calcium channels in the presynaptic regulation of noradrenaline release in rat brain cortex and hippocampus. J Neurochem 64:2567-2571.
Shupliakov O, Brodin L, Cullheim S, Ottersen OP, Storm-Mathisen J (1992) Immunogold quantification of glutamate in two types of excitatory synapse with different firing patterns. J Neurosci 12:3789-3803.

Smirnova T, Stinnakre J, Mallet J (1993) Characterization of a presynaptic glutamate receptor. Science 262:430-433.

Smith SJ, Buchanan J, Osses LR, Charlton MP, Augustine GJ (1993) The spatial distribution of calcium signals in squid presynaptic terminals. J Physiol (Lond) 472:573-593.

Swandulla D, Hans M, Zipser K, Augustine GJ (1991) Role of residual calcium in synaptic depression and posttetanic potentiation: fast and slow calcium signalling in nerve terminals. Neuron 7:915-926.

Tank DW, Regehr WG, Delaney KR (1995) A quantitative analysis of presynaptic calcium dynamics that contribute to short-term enhancement. J Neurosci 15:7940-7952.

Wickelgren WO (1977) Physiological and anatomical characteristics of reticulospinal neurones in lamprey. J Physiol (Lond) 270:89-114. 